\title{
Effects of climate change on ozone and particulate matter over Central and Eastern Europe
}

\author{
P. Huszar ${ }^{1, *}$, K. Juda-Rezler ${ }^{2}$, T. Halenka ${ }^{1}$, H. Chervenkov ${ }^{3}$, D. Syrakov ${ }^{4}$, \\ B. C. Krüger ${ }^{5}$, P. Zanis ${ }^{6}$, D. Melas ${ }^{7}$, E. Katragkou ${ }^{7}$, M. Reizer ${ }^{2}$, W. Trapp ${ }^{8}$, M. Belda ${ }^{1}$ \\ ${ }^{1}$ Department of Meteorology and Environment Protection, Charles University, 18000 Prague, Czech Republic \\ ${ }^{2}$ Faculty of Environmental Engineering, Warsaw University of Technology, 00-653 Warsaw, Poland \\ ${ }^{3}$ National Institute of Meteorology and Hydrology - branch Plovdiv, 4000 Plovdiv, Bulgaria \\ ${ }^{4}$ Department of Air and Water Pollution, National Institute of Meteorology and Hydrology, 1784 Sofia, Bulgaria \\ ${ }^{5}$ Institute of Meteorology, University of Natural Resources and Applied Life Sciences, 1190 Vienna, Austria \\ ${ }^{6}$ Department of Meteorology and Climatology, Aristotle University of Thessaloniki, 54124 Thessaloniki, Greece \\ ${ }^{7}$ Laboratory of Atmospheric Physics, Aristotle University of Thessaloniki, 54124 Thessaloniki, Greece \\ ${ }^{8}$ Air Protection Unit of Ekometria, 80-299 Gdańsk, Poland
}

\begin{abstract}
We investigated the changes in exceedances of key atmospheric pollutants due to climate change in central and southeastern Europe. The RegCM3/CAMx and ALADINCLIMATE/CMAQ regional climate-chemistry modelling systems were used for high-resolution simulations $(10 \mathrm{~km})$. The simulations performed cover 3 decadal time slices (1991-2000, 2041-2050, 2091-2100). The future simulations were driven under the A1B IPCC scenario. Our model simulations yielded changes in ozone, particulate matter with a diameter $<10 \mu \mathrm{m}\left(\mathrm{PM}_{10}\right)$ and sulphur dioxide $\left(\mathrm{SO}_{2}\right)$ resulting from climate change, without taking into consideration changes in anthropogenic emissions. We observed a shift in the average pollutant levels, and the frequency of occurrence of extreme pollution changed, especially in 2091-2100. Due to elevated air temperature, accumulated ozone exposure over the $40 \mathrm{ppbv}$ (parts per billion by volume) threshold (AOT40) for crops and forests tended to increase by up to 20 to $30 \%$ in many areas of central Europe by the end of the century. Marked increases in the number of $8 \mathrm{~h}$ ozone threshold exceedances and ozone maxima were also observed. An increase in hourly and daily $\mathrm{SO}_{2}$ exceedances was predicted. Finally, $\mathrm{PM}_{10}$ exceedances were predicted to change due to different future climate. A small change $\left( \pm 1 \mathrm{~d} \mathrm{yr}^{-1}\right)$ was calculated for an extensive area of central Europe, and exceedances decreased around the Benelux states and Romania. The modelled $\mathrm{SO}_{2}$ and $\mathrm{PM}_{10}$ changes can be partly attributed to different horizontal and vertical mixing as evidenced by changes in the ventilation coefficient (defined as the product of horizontal wind speed at the surface and the planetary boundary layer height), and the majority of the $\mathrm{SO}_{2}$ and $\mathrm{PM}_{10}$ exceedances occurred during winter and autumn.
\end{abstract}

KEY WORDS: Future air quality - Climate change ' Pollutant exceedances - Ozone · Particulate matter · Coupled climate-chemistry models

Resale or republication not permitted without written consent of the publisher

\section{INTRODUCTION}

Projecting air quality for future decades is a challenging subject, due to its complex and multifaceted nature. Many factors influence air quality, and very often interference and masking effects make the processes of understanding the contribution of each factor separately quite difficult. Firstly, changes in emissions can lead to different amounts of primary pollutants present in the air, and this can further alter 
the production/destruction of secondary pollutants. Secondly, air quality can be influenced by the state of the atmosphere, i.e. by the meteorological/climatic conditions. This influence can be direct, meaning that the change in the magnitude of meteorological parameters (e.g. temperature, radiation, precipitation, mixing height) directly affects chemical production and loss processes as well as physical removal processes. Dawson et al. (2007) and Hedegaard et al. (2008) found that temperature has one of the largest effects among the meteorological parameters. Krüger et al. (2008) also reported that increases in temperature and radiation were the most important factors for the projected ozone increase in the 21st century. Change in circulation patterns at global and synoptic scales as a result of climate change is another factor that can affect pollution levels. For example, changes in Brewer-Dobson circulation in a future climate may also affect the stratosphere-troposphere exchange, thereby also affecting the chemical composition of the troposphere (Collins et al. 2003, Stevenson et al. 2006). However, meteorology can also influence atmospheric chemical composition indirectly through biogenic emissions of hydrocarbons which also have a strong impact on photochemical processes in the troposphere. Concerning the indirect influence, Meleux et al. (2007) studied summer European ozone formation and found that increases in biogenic emissions due to temperature rise contributed to more frequent elevated ozone occurrence. Fiore et al. (2005) also emphasised the role of temperature change in ozone formation through the modulation of biogenic hydrocarbon emissions.

It is now well established that significant environmental changes are expected in the future (IPCC 2007). These changes will bring modified meteorological conditions compared to the present. As noted above, acting in a modified driving environment, tropospheric chemistry processes are expected to change as well. Therefore, a shift in the pollutant concentration distribution can be expected.

Quantifying the effect of a changing climate on air quality and chemistry requires the use of climatechemistry models or chemistry transport models (CTMs) coupled to climate models. Numerous studies have dealt with future air quality projections on a global scale using coupled climate-chemistry models. Most of them focused on ozone on a global scale (Hauglustaine et al. 2005, Stevenson et al. 2006, Racherla \& Adams, 2006, 2008), while Hedegaard et al. (2008) also provided results for sulphur and nitrogen dioxide $\left(\mathrm{SO}_{2}\right.$ and $\left.\mathrm{NO}_{\mathrm{x}}\right)$. Other studies have provided information on regional- and local-scale air quality changes (Szopa et al. 2006, Meleux et al. 2007, Nolte et al. 2008, Andersson \& Engardt 2010). These focused on the average species concentration change, but only few results were given regarding the impact on the occurrence of extreme air pollution events. A recent report issued by the U.S. Environmental Protection Agency (USEPA) assessing the regional impact of climate change on U.S. air quality indicated that the number of high ozone situations will increase in the future, potentially causing air quality alerts earlier in spring and later in the autumn (USEPA 2009). The increased frequency of elevated ozone levels due to higher temperatures in the future climate has been shown by many others as well (Bell et al. 2007, Mahmud et al. 2008, Zlatev 2009).

In this study, we dealt with the assessment of climate change impacts on air quality in central and southeastern Europe. We focused mostly on the extremes regarding air pollution on a regional scale. Besides ozone, the focus was also on particulate matter with a diameter under $10 \mu \mathrm{m}\left(\mathrm{PM}_{10}\right)$ and $\mathrm{SO}_{2}$ as a precursor for aerosol formation. Setting up highresolution domains on targeted areas over central and southeastern Europe and running CTMs offline coupled to regional climate models for present conditions and selected future decades, we assessed the response of air pollution to climate change. We evaluated this response by means of exceedances of pollutant thresholds in the present and future climate conditions in the above-mentioned regions. The work is based on the modelling concept described by Juda-Rezler et al. (in press).

\section{METHODOLOGY}

The basic idea of our approach lies in an appropriate application of chemistry transport models on regional scales driven by regional climate models for selected present and future decades. A detailed description of the theoretical base and modelling tools applied is given by Juda-Rezler et al. (in press).

\subsection{Overview of the concept and the experimental design}

The regional climate models involved in the study were RegCM3 (Pal et al. 2007) and ALADIN-CLIMATE (Syrakov et al. 2010). The first model was coupled offline to the chemistry transport model CAMx (www.camx.com), the second one to the model CMAQ (www.cmaq-model.org). 
Four domains with a horizontal resolution of $10 \times$ $10 \mathrm{~km}$ were set up to cover the targeted areas (sizes of grids [no. of columns $\times$ no. of rows; unitless] in parentheses): the larger central European region centering on the Czech Republic $(183 \times 162)$; Poland $(118 \times 107)$; Hungary $(118 \times 98)$; and Bulgaria $(54 \times$ 40). These domains and their corresponding runs are referred to as Czech, Polish, Hungarian and Bulgarian domains. The RegCM3/CAMx couple was applied over the first 3 domains. The Bulgarian domain was computed by the ALADIN-CLIMATE/ CMAQ couple, as an alternative. The Czech domain dominated in size and encompassed almost all other domains. Evaluating the environmental changes with several model configurations and 1 additional model couple helps to increase the robustness of the results. Throughout the paper, if not mentioned explicitly, the Czech domain will be considered.

Four decadal simulations were performed using the above-mentioned models and their couples over each domain. The present decade (1991-2000) was simulated twice, with different meteorological forcing: ERA-40 reanalysis and ECHAM5 as a global climate model (GCM)-driven control experiment. These 2 runs will be referred to hereafter as the ECHAM and ERA runs, respectively. Since the ERA40 reanalysis project (Uppala et al. 2005) is a global atmospheric analysis of observations and satellite data streams, it can be considered to be closer to real atmospheric conditions and thus is used as the reference run for modelling system validation. The control simulation (ECHAM run) for the same decade gave a basis for comparison between present and future. Finally, 2 runs forced by ECHAM5 model fields were performed for the decades 2041-2050 and 2091-2100, which we will refer to as near and far future decades, respectively. The meteorological runs were part of longer, 40 yr simulations starting in the years 1961, 2011 and 2061 for the 3 analyzed decades. The chemistry was integrated from 1990, 2040 and 2090, allowing a 1 yr spin-up time.

The model RegCM3 was run over 23 layers reaching $10 \mathrm{hPa}$, while CAMx ran over the lowermost 12 levels only. For convective parameterisation, the Grell scheme was applied (Grell 1993). In the chemistry model, we invoked the Carbon Bond IV chemical mechanism (Carter 1996). Aerosol processes were treated by the ISORROPIA thermodynamic equilibrium model (Nenes et al. 1998). A meteorological preprocessor utility (RegCM2CAMx; described and applied by e.g. Krüger et al. 2008, Katragkou et al. 2010) was developed to convert RegCM3 output fields to fields that CAMx requires for driving its transport, diffusion, deposition and chemistry.
Hourly anthropogenic emissions were obtained from the European Monitoring and Evaluation Programme (EMEP) database (Vestreng et al. 2005) with a combination of $5 \times 5 \mathrm{~km}$ resolution emissions data for central Europe (Winiwarter \& Zueger 1996). We considered emission for $\mathrm{NO}_{\mathrm{x}}$, non-methane volatile organic compounds (NMVOC), ammonia $\left(\mathrm{NH}_{3}\right)$, carbon monoxide $(\mathrm{CO}), \mathrm{SO}_{2}$, particles with a diameter $<2.5 \mu \mathrm{m}$ (PM2.5) and particles with a diameter $>2.5$ $\mu \mathrm{m}$ and $<10 \mu \mathrm{m}$ (PMcoarse). They were set to year 2000 values during all decades to isolate the effect of climate change on air quality. This is an important point that distinguishes this study from studies that attempt to make projections of future air quality. Significant emission reductions are expected in the future as a result of implementing restricting policies. This applies to ozone precursors and also to $\mathrm{SO}_{2}$ and black and organic carbon emissions that are contributing the overall changes of $\mathrm{PM}_{10}$ (Riahi et al. 2007). Fig. 1 illustrates the normalised time series of the annual EMEP emissions averaged over Austria, the Czech Republic, Poland, Slovakia, Hungary and Bulgaria, i.e. the countries that we focused on in this study. The absolute values for 1991 are (in $\mathrm{Gg} \mathrm{yr}^{-1}$ ) 1314.8, 509.6, 1507.2, 322.71 and 154.1 for $\mathrm{SO}_{2}, \mathrm{NO}_{\mathrm{x}}$, $\mathrm{CO}, \mathrm{NMVOC}$ and $\mathrm{NH}_{3}$, respectively; and for 1999 for PM2.5 and PMcoarse: 51.5 and 42.7, respectively. It is clear that emissions tend to decrease during the years 1991-2020, and a further decrease is expected in the following decades of the 21st century.

The future air quality changes will therefore be a result of the combined effect of modified emissions and climatic conditions. We attempted to evaluate the second aspect of the changes, viz. the impact of modified climate, and this requires fixing the anthropogenic emissions on a constant level. The same approach, i.e. fixing emissions in the present levels, was applied by e.g. Hedegaard et al. (2008), Racherla \& Adams (2008) and Andersson \& Engardt (2010).

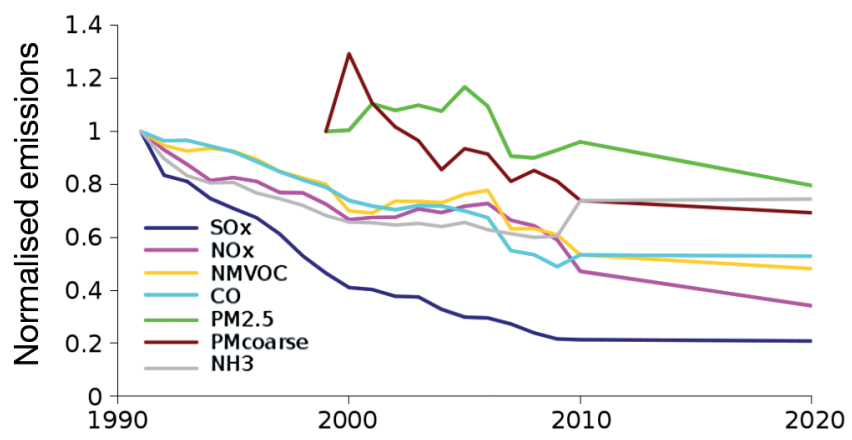

Fig. 1. Normalised time series of the EMEP emissions averaged for Austria, the Czech Republic, Poland, Slovakia, Hungary and Bulgaria 
Biogenic hydrocarbon emissions evolved according to the actual meteorological conditions in each decade. They were computed following Guenther et al. (1993), considering isoprene and monoterpenes. Chemical boundary conditions for all $10 \times$ $10 \mathrm{~km}$ resolution domains were taken from lowerresolution chemistry runs performed on a $50 \mathrm{~km}$ spatial resolution domain covering most of Europe described by Krüger et al. (2008) and Katragkou et al. (2010).

A detailed description of the modelling system applied for the Bulgarian domain is provided by Syrakov et al. (2010).

\subsection{Air quality criteria}

The impact of air quality on ecosystem and human health can be assessed using suitable measures. For quantifying the exposure of the ecosystem, particularly crops and forests, to elevated ozone levels, a widely used measure, viz. accumulated exposure over the threshold (AOT), can be used that was introduced in the mid-90s (Fuhrer et al. 1997). It is an accumulated exposure index over a certain ozone concentration. In this study, we evaluated the present and future AOT for the threshold of $40 \mathrm{ppbv}$. The calculation of the AOT40 considers only daylight hours, when stomata are open and uptake of ozone by vegetation occurs. For Europe, these are 08:00 to 20:00 h Central European Time (CET). For crops, the corresponding AOT40 $0_{\text {crop }}$ is defined as the following integral

$$
\mathrm{AOT} 40_{\mathrm{crop}}=\int_{T}[c(t)-40] \mathrm{d} t
$$

where $c(t)$ denotes the hourly ozone concentration in ppbv, and we integrated through all hours (denoted by $T$ ) from May to July between 08:00 and 20:00 $\mathrm{h}$ local time whenever $c(t) \geq 40$ ppbv. A similar definition holds for forest when the integration is done from April to September.

Another criterion used in this study was the number of exceedances of hourly and daily pollutant concentration thresholds. All considered measures were implemented in the European Union Framework Directive on ambient air quality assessment and management (96/62/EC) along with its daughter directives (1999/30/EC and 2002/3/EC) and are now established in the Directive on ambient air quality and cleaner air for Europe (2008/50/EC). These directives define limit values (LVs) as annual, daily or hourly averaged concentration thresholds which
Table 1. EU air quality thresholds (in $\mu \mathrm{g} \mathrm{m}^{-3}$ ) for different averaging intervals of the allowed number (hours or days) of pollutant exceedances following Flemming \& Stern (2007). $\mathrm{PM}_{10}$ : particulate matter with a diameter $<10 \mu \mathrm{m}$. (-): no threshold value defined

\begin{tabular}{|lcccc|}
\hline Average interval & $\mathrm{O}_{3}$ & $\mathrm{NO}_{2}$ & $\mathrm{SO}_{2}$ & $\mathrm{PM}_{10}$ \\
\hline Hourly & - & 200 & 350 & - \\
Daily & $120(8 \mathrm{~h}$ max. $)$ & - & 125 & 50 \\
Annual & - & 40 & 20 & 40 \\
\hline
\end{tabular}

should not be exceeded on more than a given number of occasions (Table 1). The tolerated number of exceedances (for health protection) per year is: 25 for maximum daily $8 \mathrm{~h}$ ozone (averaged over 3 yr, i.e. 75 over a 3 yr period), 18 for the hourly NO threshold, 24 and 3 for the hourly and daily $\mathrm{SO}_{2}$ thresholds, respectively, and 35 for daily $\mathrm{PM}_{10}$ threshold.

The maximum AOT40 value for the protection of vegetation is $3000 \mathrm{ppbv} \cdot \mathrm{h}$ for crops, while the recommended threshold for forests is $10000 \mathrm{ppbv} \cdot \mathrm{h}$ (2002/3/EC).

\section{PRESENT-DAY CONDITIONS}

In this section, we provide the values of the previously described criteria averaged over the years 1991-2000 from the ERA run and a comparison of the simulated concentrations from the same run with EMEP measurements in order to prove the model's ability to reasonably reproduce the distribution of the species examined in this study. A more detailed model performance evaluation is provided by JudaRezler et al. (in press); here we present only the main strengths and deficiencies identified in the models, focusing on the air quality criteria described in the previous section.

For the European $50 \mathrm{~km}$ spatial step domain that provided chemical boundary conditions for our $10 \mathrm{~km}$ runs, validation of the RegCM3/CAMx modelling system was already performed by Katragkou et al. (2010). In the latter work, the model simulations are forced firstly by ERA40 reanalysis and then by ECHAM global model output. Average decadal surface ozone of both simulations was validated against the EMEP measurements, and the results showed that both simulations reproduce the basic spatial and temporal patterns of the measurements in an acceptable way.

We did not carry out validation of the ECHAM run over the 1991-2000 decade. To justify the ability of 
the modelling system to reproduce the examined species concentrations, we selected the ERA40 meteorological boundary condition as the best available (meteorological) input. However, from Katragkou et al. (2010), it is clear that the accuracy of the chemical fields produced by the modelling system remained acceptable when we chose the less accurate meteorological forcing of a GCM output, with respect to the ERA40 reanalysis.

Results for particulate matter over the Polish domain were preliminarily validated by Juda-Rezler et al. (2010), showing acceptable reproduction of the particulate matter levels by the RegCM3/CAMx modelling system. The initial validation for the Bulgarian domain runs carried out by the ALADINCLIMATE/CMAQ modelling system was presented by Syrakov et al. (2010).

\subsection{Ozone}

First we evaluated the AOT40 for crops and forest plotted in Fig. 2. The values range from 3000 to $35000 \mathrm{ppbv} \cdot \mathrm{h}$ for crops, being high over the southern part of Europe. AOT40 for forests reaches higher values due to a longer integration period and has maxima around $50000 \mathrm{ppbv} \cdot \mathrm{h}$, again in southern Europe. Values are higher over the sea and mountainous regions; however, due to the absence of terrestrial vegetation over these areas, this index has no relevance.

The number of $8 \mathrm{~h}$ ozone exceedances per year averaged over the decade 1991-2000 is plotted in Fig. 3a. On the large part of the domain, the values lie between 1 and $5 \mathrm{~d} \mathrm{yr}^{-1}$. No exceedances are mod- elled in the eastern part of the domain, and the highest values occur over northern Italy (up to $50 \mathrm{~d} \mathrm{yr}^{-1}$ ) and the surrounding sea (up to $80 \mathrm{~d}$ ); however, this threshold for human health protection does not have importance over sea.

\subsection{Sulphur dioxide}

Although this study focuses on ozone and $\mathrm{PM}_{10}$, we also provide some results concerning $\mathrm{SO}_{2}$, as it is a direct precursor for sulphate aerosol formation which comprises an important fraction of fine particulate matter $\left(\mathrm{PM}_{2.5}\right)$ in the air. Air pollution caused by $\mathrm{SO}_{2}$ is regulated by 3 thresholds: $350 \mathrm{\mu g} \mathrm{m}^{-3}$ for average hourly $\mathrm{SO}_{2}, 125 \mathrm{\mu g} \mathrm{m}^{-3}$ for daily average $\mathrm{SO}_{2}$, and finally, the $20 \mathrm{\mu g} \mathrm{m}^{-3}$ annual threshold. The average numbers of both hourly and daily exceedances during 1991-2000 are plotted in Fig. 3b,c for the daily and hourly limits. The highest number of exceedances is modelled around the hotspots of the highest $\mathrm{SO}_{2}$ emissions and average concentrations, often reaching $100 \mathrm{~h} \mathrm{yr}^{-1}$ or $40 \mathrm{~d} \mathrm{yr}^{-1}$. This is a serious overrun of the operative EU regulations. The worst affected regions, where annual thresholds are exceeded are southern Poland, northern Hungary and the countries on the Balkan Peninsula (Fig. 3d). In western European countries, where strict air quality regulations were applied earlier, large areas of $\mathrm{SO}_{2}$ exceedances do not occur, except in small regions around the Benelux states.

The comparison between exceedances of the $\mathrm{SO}_{2}$ annual threshold calculated for the present-day decade in the Bulgarian (Fig. 4a), Polish (Fig. 4b) and Czech (Fig. 3d) domains highlights the differences in

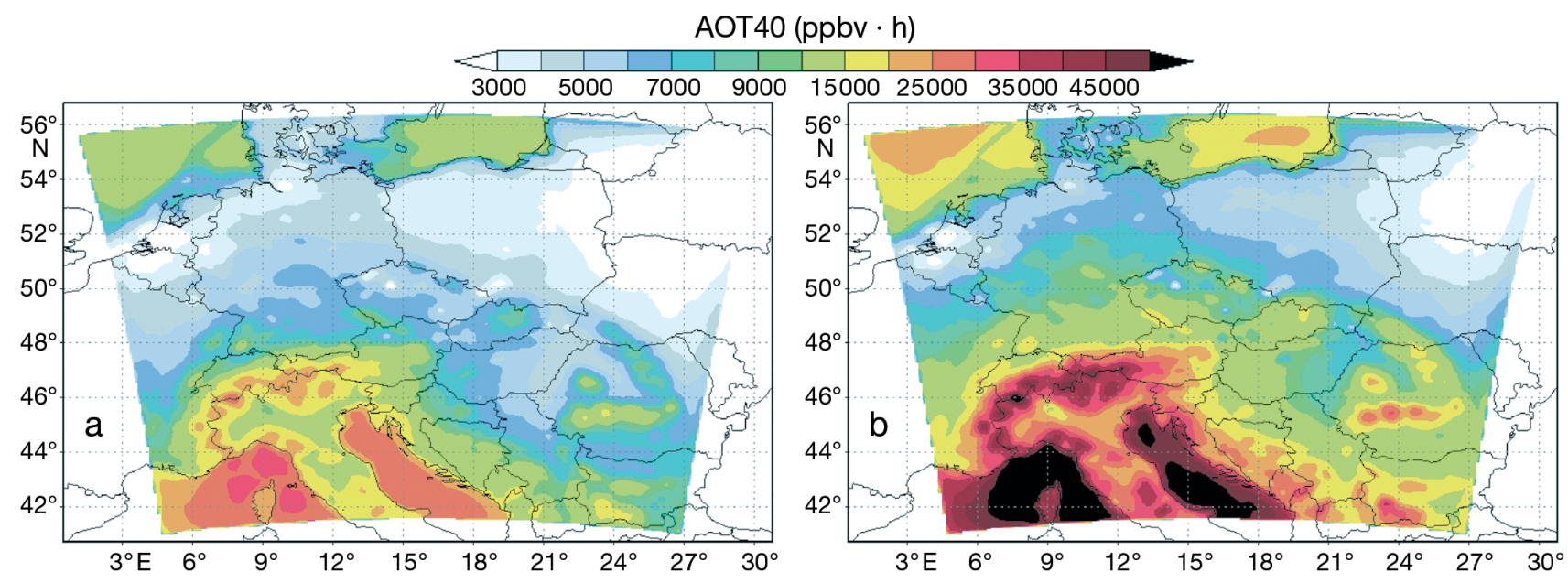

Fig. 2. Exposure of (a) crops and (b) forests to ozone levels above $40 \mathrm{ppbv}$ (AOT40) in ppbv · h, averaged over 1991-2000 (ERA run) 
No. d $8 \mathrm{~h}$ mean $\mathrm{O}_{3}>120 \mu \mathrm{g} \mathrm{m}^{-3}$

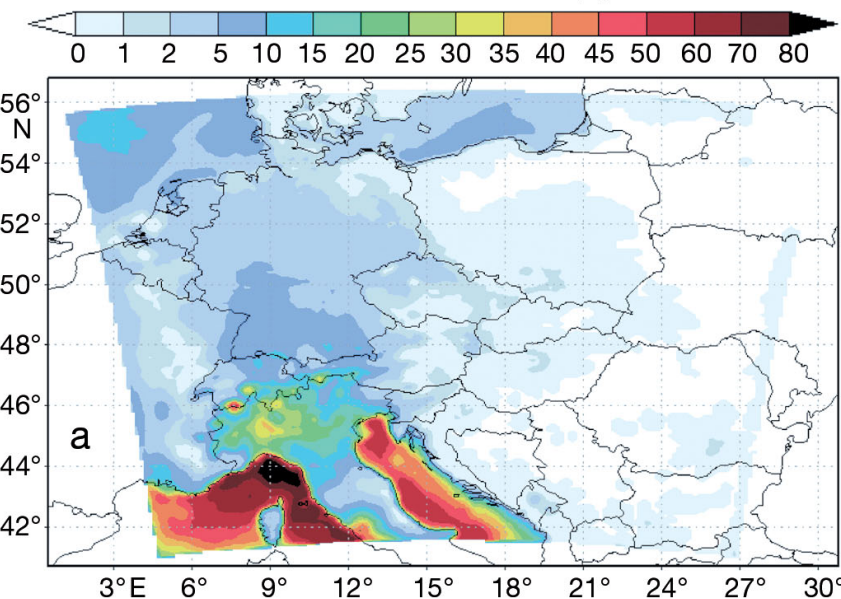

No. $\mathrm{h} \mathrm{SO}_{2}>350 \mu \mathrm{g} \mathrm{m}^{-3}$

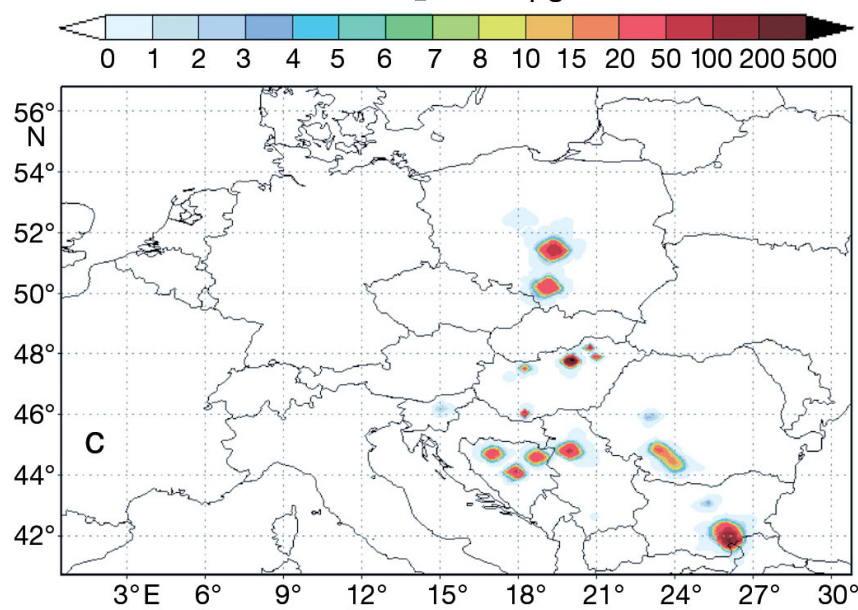

No. $\mathrm{d} \mathrm{SO}_{2}>125 \mu \mathrm{g} \mathrm{m}^{-3}$
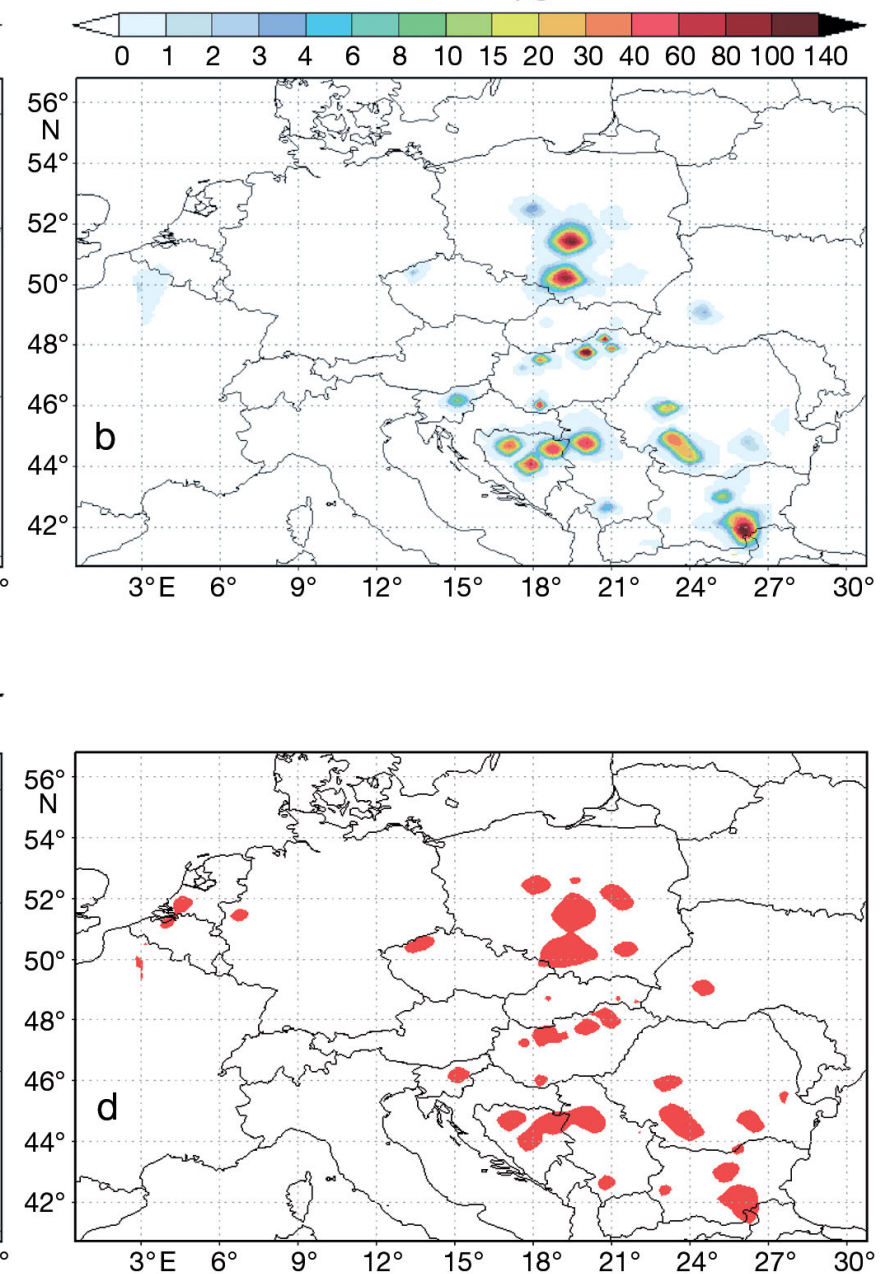

Fig. 3. Threshold exceedances for ozone and $\mathrm{SO}_{2}$ averaged over 1991-2000 (ERA run): (a) number of days per year with maximum $8 \mathrm{~h}$ running ozone levels higher than $120 \mu \mathrm{g} \mathrm{m}^{-3}$; number of (b) days and (c) hours per year with $\mathrm{SO}_{2}$ levels exceeding thresholds of 125 and $350 \mu \mathrm{g} \mathrm{m}^{-3}$, respectively; (d) areas (in red) where the annual EU threshold of $20 \mathrm{\mu g} \mathrm{m}^{-3}$ for $\mathrm{SO}_{2}$ was exceeded

the set-up of the modelling systems. The Polish and Bulgarian large point sources (LPSs) were treated either individually (Poland) or as elevated area sources (Bulgaria) in the simulations, while for all countries in the Czech domain, point sources were treated as surface area sources, thus causing significant overestimation in the vicinity of the LPS. The differences in estimated exceedance areas obtained in runs on Czech and Polish domains are exclusively due to differences in emission inputs, as both the Czech and Polish domains were treated using the same modelling system (RegCM3/CAMx). The slight differences obtained in the Czech and Bulgarian runs (larger areas with exceedances of LVs in Czech runs) are additionally due to different modelling systems applied.

\subsection{Particulate matter}

Particulate matter modelled by the presented couples comprised sulphates, nitrates, ammonium aerosols, black and organic carbon, coarse and fine inert aerosols and 5 types of secondary organic aerosol. In Fig. 5a, the average surface concentration of $\mathrm{PM}_{10}$ is plotted for the 1991-2000 period as modelled in the perfect boundary run. The colour scale ends at $40 \mu \mathrm{g}$ $\mathrm{m}^{-3}$, which is the annual threshold. It is apparent that this threshold is exceeded only over minor areas around the Benelux states, southern Poland, northern Italy and Romania. Daily $\mathrm{PM}_{10}$ exceedances (Fig. 5b) up to $10 \mathrm{~d} \mathrm{yr}^{-1}$ averaged over the decade 1991-2000 are modelled in the Benelux countries, northern Germany and northern Italy. In Romania, 

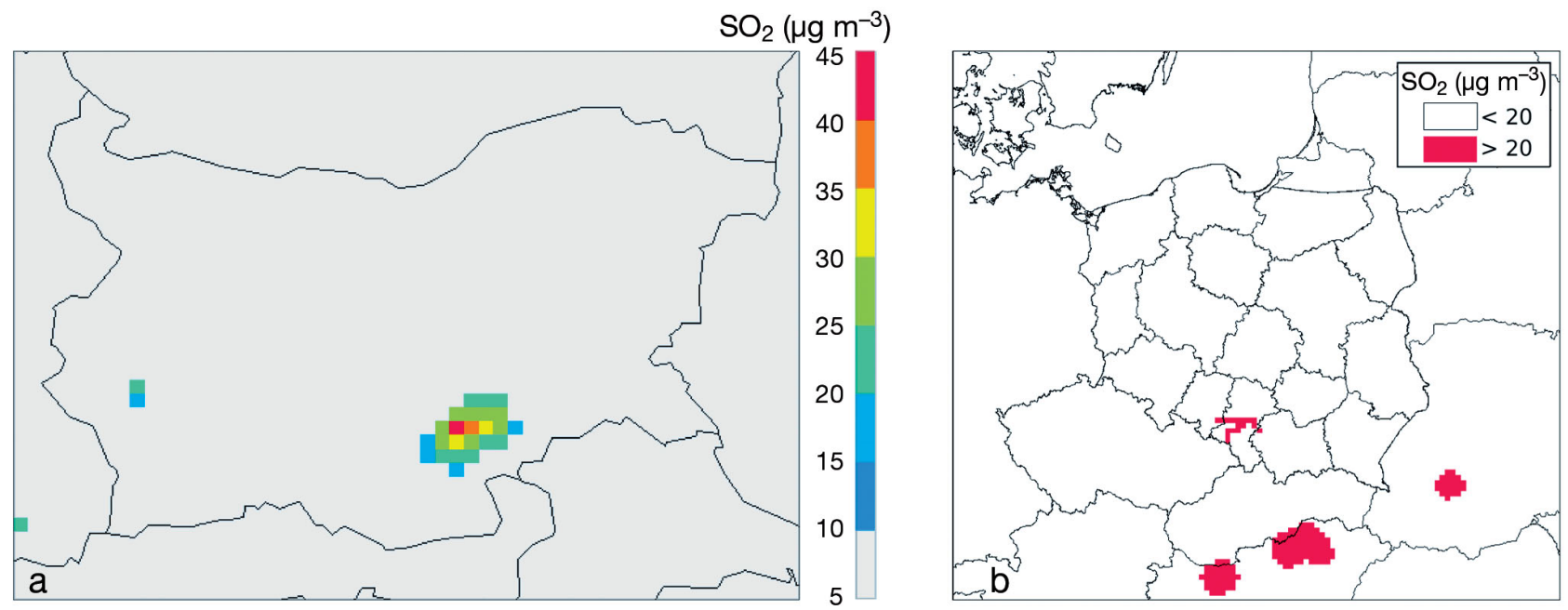

Fig. 4. $\mathrm{SO}_{2}$ measures averaged over 1991-2000: (a) annual $\mathrm{SO}_{2}$ levels for the Bulgarian domain; (b) exceedances of the $\mathrm{SO}_{2}$ annual threshold of $20 \mu \mathrm{g} \mathrm{m}^{-3}$ for the Polish domain
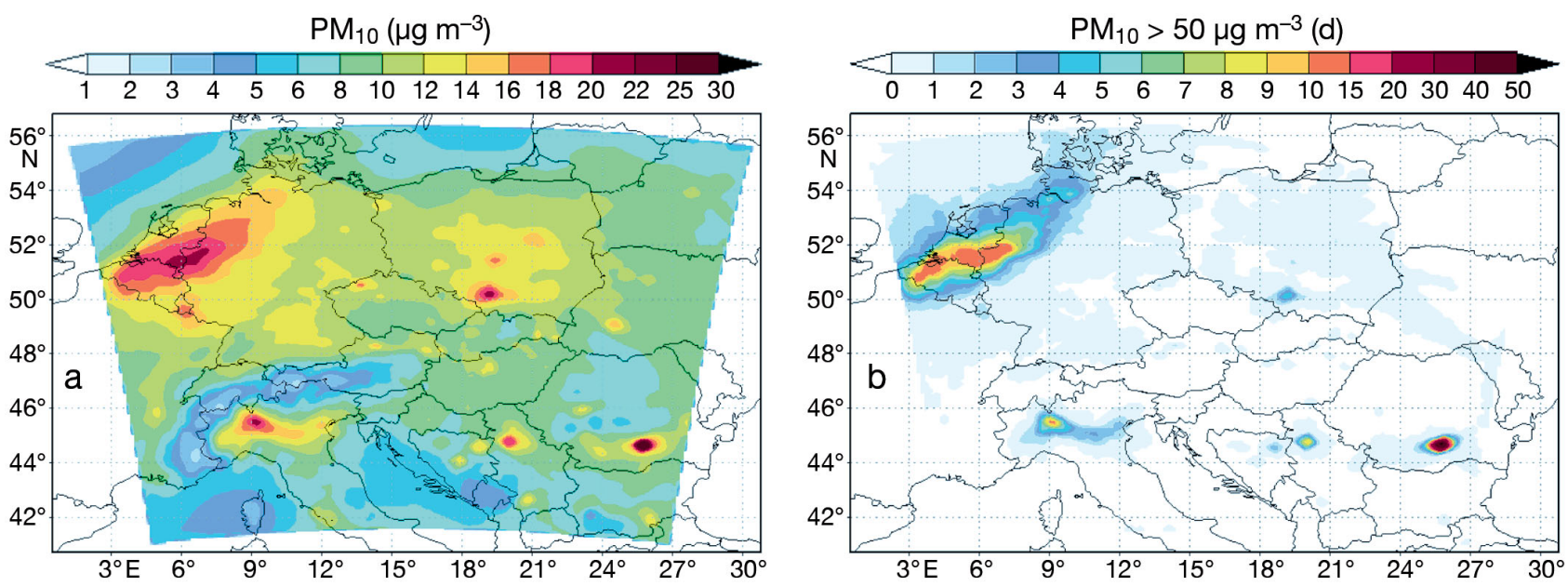

Fig. 5. Measures of particulate matter with a diameter $<10 \mu \mathrm{m}\left(\mathrm{PM}_{10}\right)$ averaged over 1991-2000 in ERA runs: (a) surface PM 10 levels as the annual average; (b) number of days when $\mathrm{PM}_{10}$ surface levels exceeded $50 \mathrm{\mu g} \mathrm{m}^{-3}$

around its capital Bucharest, the number of daily $\mathrm{PM}_{10}$ exceedances reaches $50 \mathrm{~d} \mathrm{yr}^{-1}$.

\subsection{Model performance evaluation}

EMEP rural background stations were selected for model-measurement comparison. The AOT40 values for crops and forest averaged over the 1991-2000 decade are compared to measurements in Fig. 6a. The scatter plot shows that our model underestimated AOT40 usually by a factor of 2. Stations with hourly ozone data from this decade were chosen mainly from Germany and central Europe (due to temporal coverage of the entire decade) where high AOT40s were reported compared to the actual target values $(3000 \mathrm{ppbv} \cdot \mathrm{h}$ for crops and $10000 \mathrm{ppbv} \cdot \mathrm{h}$ for forest) for this decade (Hunova et al. 2003, EMEP 2010). Better agreement was achieved at the Ispra station in Italy, as over the Mediterranean region, our model predicted relatively high values of AOT40 which correspond with the values for this decade reported by EMEP (2010). The weakness of the model to accurately simulate AOT40 levels lies in its inability to resolve the diurnal ozone variation seen in Fig. 6b for selected stations: between 08:00 and 20:00 $\mathrm{h}$, the modelled ozone exceedance over $80 \mu \mathrm{g}$ $\mathrm{m}^{-3}$ (40 ppbv) is approximately half of the measured one, leading to $50 \%$ underestimation of AOT40. The main reason for this could be that meteorology was provided to the chemistry model every 6th hour at 00:00, 06:00, 12:00 and 18:00 h UTC. Between these 

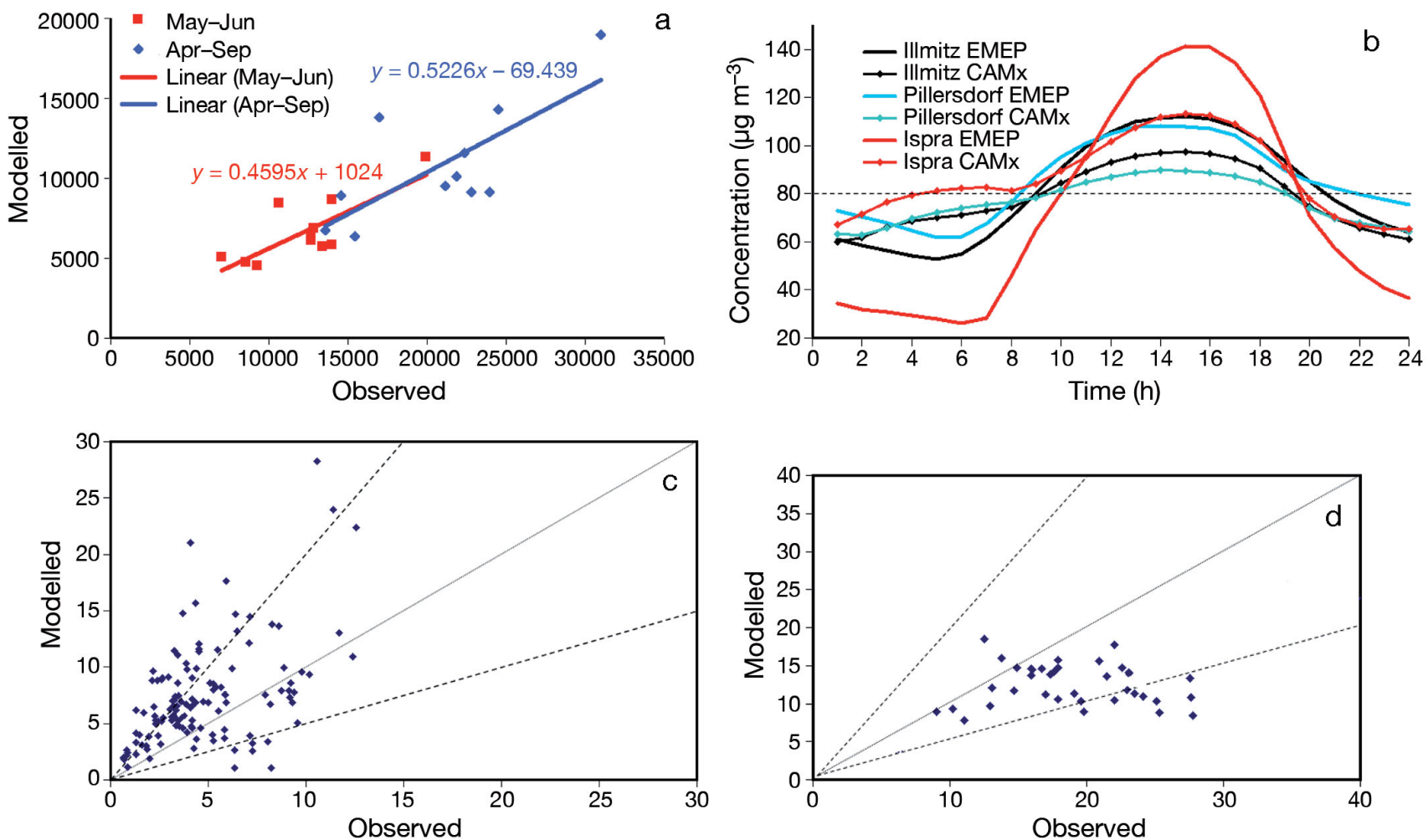

Fig. 6. Validation of the RegCM3/CAMx modelling system on EMEP station observations: (a) AOT40 exposure index (ppbv · h) defined for crops (red) and forests (blue) averaged over 1991-2000 with trends. (b) Diurnal ozone variation for 1991-2000 summer average for selected stations (dashed line at $80 \mu \mathrm{g} \mathrm{m}^{-3}$ indicates the $40 \mathrm{ppbv}$ threshold). (c) 1991-2000 average winter $\mathrm{SO}_{2}$ concentrations in $\mu \mathrm{g} \mathrm{m}{ }^{-3}$. (d) Year 2000 average $\mathrm{PM}_{10}$ concentrations in $\mu \mathrm{g} \mathrm{m}^{-3}$. Dashed lines in (c,d) indicate the model-observation ratio of 2 and 0.5 , while grey solid lines indicate the ideal ratio

times, it was linearly interpolated within CAMx. The daily maximum temperatures and peak ozone concentration usually occur in afternoon hours and cannot be captured if both 12:00 and 18:00 UTC temperatures are below the daily maxima. Further, we rely on the assumption that the model preserves this systematic behaviour (peak ozone underestimation) in the future and thus the relative change will be modelled with a reasonable accuracy by eliminating this model deficiency.

Due to lower daily maximum ozone values, the number of days with ozone exceedances is underestimated as well. However, recalling the assumption above, the relative changes in future decades due to climate change may eliminate this model behaviour. The modelled spatial pattern of exceedances for ozone, regardless of their magnitude, is in a good agreement with that reported by EMEP (2010).

The comparison of $\mathrm{SO}_{2}$ exceedances with station data was complicated by the unavailability of long-term measurements over areas where these exceedances occurred (eastern Europe). Data avail- able over other areas therefore served to compare other quantities: we chose the average winter $\mathrm{SO}_{2}$, as $\mathrm{SO}_{2}$ exceedances in our simulation occurred mainly in winter. The scatter plot in Fig. 6c shows that the model overestimates the winter concentrations of $\mathrm{SO}_{2}$. This is mainly due to treatment of large $\mathrm{SO}_{2}$ emitting point sources as surface area sources, which directly increases the $\mathrm{SO}_{2}$ concentrations in the surface layer. Indeed, lower concentrations and fewer exceedances were simulated over the Polish domain where point sources were considered explicitly and were not included in the area emissions.

As $\mathrm{PM}_{10}$ measurements over rural background stations in central and eastern Europe were available mainly from the late 1990s, the comparison is limited to the year 2000. Fig. 6d presents the scatter plot for annual $\mathrm{PM}_{10}$. It underlines the weakness of the RegCM3/CAMx modelling system, i.e. the underestimation of $\mathrm{PM}_{10}$ values, often by a factor of 2 . A similar underestimation was reported by other studies as well (e.g. Denby et al. 2008). 
Due to lower average values, the number of daily threshold exceedances is underestimated as well. The model simulated up to $15 \mathrm{~d} \mathrm{yr}^{-1}$ for the Benelux region, while EMEP (2010) reported values around 30 to $40 \mathrm{~d} \mathrm{yr}^{-1}$. Even larger underestimations occurred over Germany and Poland, with up to 6 modelled days per year with $\mathrm{PM}_{10}$ over $50 \mu \mathrm{g} \mathrm{m} \mathrm{m}^{-3}$ compared to 10 to $30 \mathrm{~d} \mathrm{yr}^{-1}$ in EMEP data. However, as discussed in Section 4.4, one of the main regions with larger changes in $\mathrm{PM}_{10}$ exceedance as a result of climate change is the Benelux countries, and this is the region where the model performed most accurately.

One reason for this underestimation may be disregarding the soil dust and sea salt particles that can significantly contribute to European $\mathrm{PM}_{10}$ levels (Querol et al. 2004). The concentrations of organic aerosols are probably also underpredicted. Simpson et al. (2007) found this to be a common deficiency in air quality models, and the reason for this lies in the poor model representation of the mechanism of secondary organic aerosol formation with numerous uncertain parameters.

Underpredcition of $\mathrm{PM}_{10}$ does not lie in the inadequate representation of vertical mixing. To calculate vertical eddy viscosity coefficients for CAMx, we used the method of O'Brien (1970) that tends to underpredict vertical mixing leading to higher concentrations (Byun et al. 2007, Baker et al. 2008) at the surface. Thus, one can expect that this does not play a role in negative model bias for $\mathrm{PM}_{10}$, and a similar conclusion can also be made for ozone (negative bias in predicting daily maximum values). On the other hand, this model deficiency can contribute to overpredictions of $\mathrm{SO}_{2}$, especially when considering the fact that at higher levels (where these emissions should be emitted), the negative bias of eddy viscosity coefficients calculated by O'Brien (1970) becomes small (Baker et al. 2008).

\section{CLIMATE CHANGE IMPACT ON AIR QUALITY}

\subsection{Selected features of the modelled climate change}

Here we present the main features of the climate change impact on those atmospheric quantities that had the largest contribution to the air quality changes presented below.

The simulated $2 \mathrm{~m}$ temperature changes for near and far future summer are presented in Fig. 7. Warming in summer dominates in both future decades with respect to the 1991-2000 decade. In the near future, it reaches $2^{\circ} \mathrm{C}$ over southern Europe and the Balkan Peninsula. Over the rest of Europe, it usually lies between 0.2 and $0.8^{\circ} \mathrm{C}$. For the decade 2091-2100, warming is more pronounced over the entire domain, ranging from 2 to $4^{\circ} \mathrm{C}$.

The summer average incident shortwave radiation (Fig. 8) that influences summer photochemistry and ozone formation will change only slightly in the near future, encompassing a decrease by 2 to $10 \mathrm{~W} \mathrm{~m}^{-2}$ over central Europe and an increase up to $10 \mathrm{~W} \mathrm{~m}^{-2}$ over the Balkan Peninsula and Italy. In the far future, a larger increase of incident solar radiation occurs on the surface over the entire domain, with values exceeding $15 \mathrm{~W} \mathrm{~m}^{-2}$ over the southern and western parts of the domain (Balkan Peninsula, Italy and Germany), representing a relative increase from 5 to $10 \%$.

Fig. 9 presents a change of $10 \mathrm{~m}$ wind components (zonal and meridional) for the near and far future averaged over winter and autumn, i.e. the seasons with the highest number of $\mathrm{SO}_{2}$ and $\mathrm{PM}_{10}$ exceedances in our simulations. In the near future, an increase of zonal wind occurs up to $1 \mathrm{~m} \mathrm{~s}^{-1}$. The meridional wind decreases by 0.2 to $0.6 \mathrm{~m} \mathrm{~s}^{-1}$, mainly over the northern part of the domain (Czech Republic, Germany and Poland). In the far future, zonal
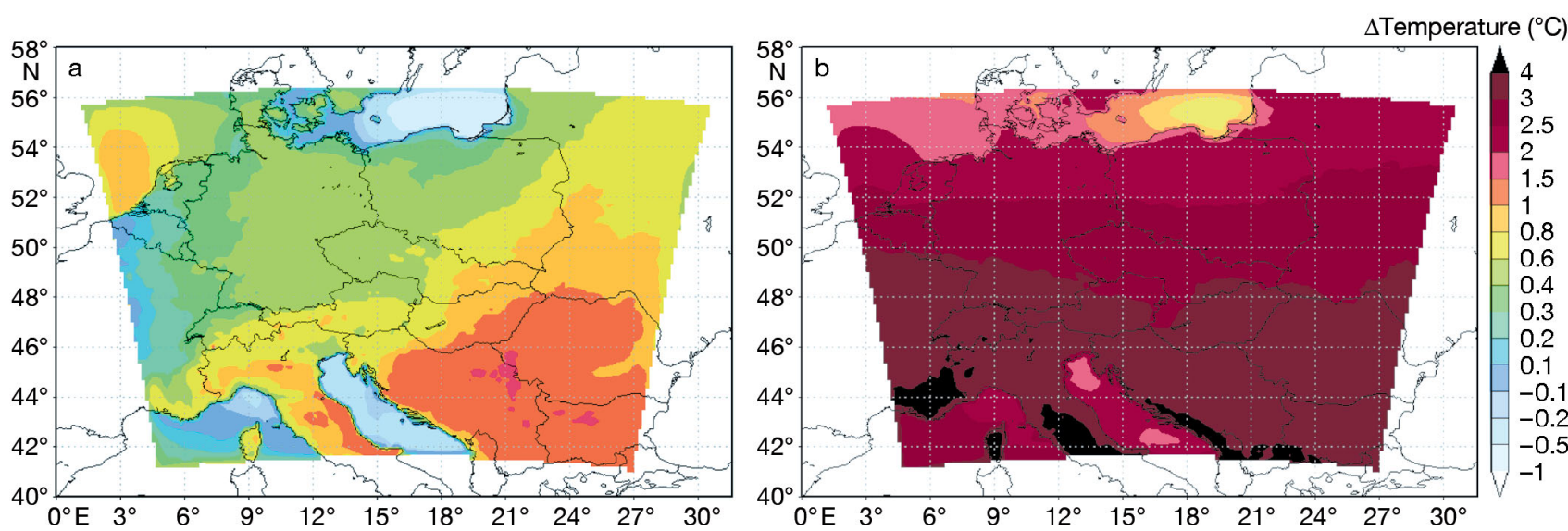

Fig. 7. Change in average $2 \mathrm{~m}$ summer (JJA) temperature between (a) 2041-2050 or (b) 2091-2100 and 1991-2000 (ECHAM runs) 

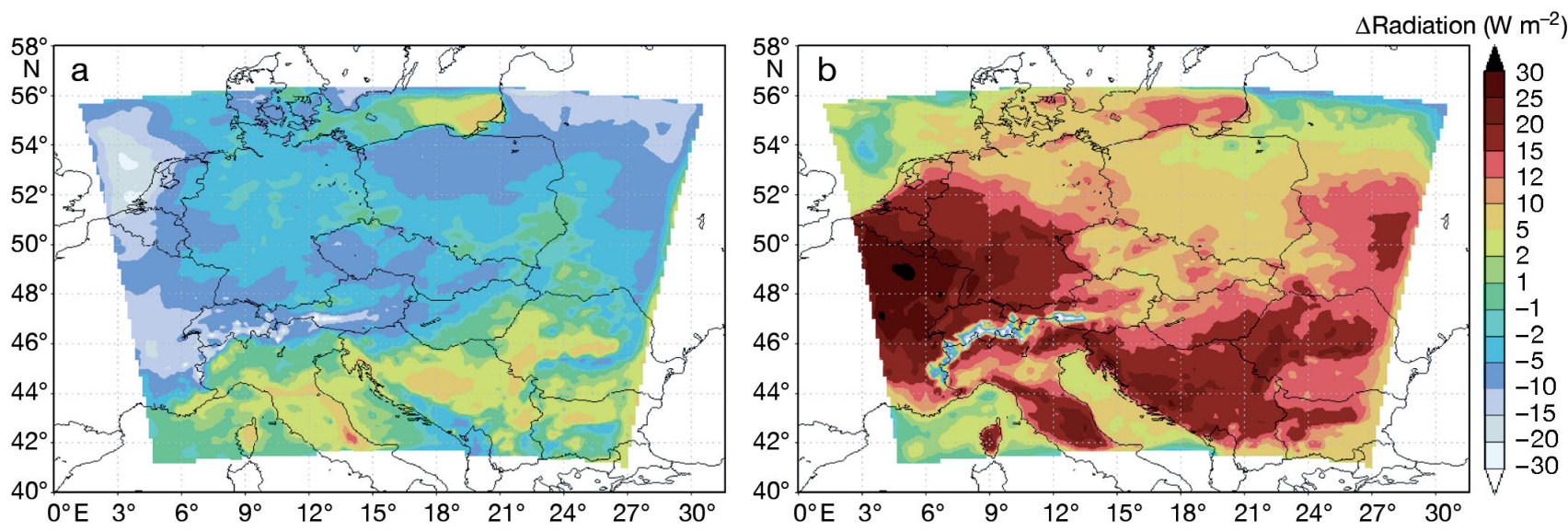

Fig. 8. Change in summer (JJA) incident solar radiation between (a) 2041-2050 or (b) 2091-2100 and 1991-2000 (ECHAM runs)
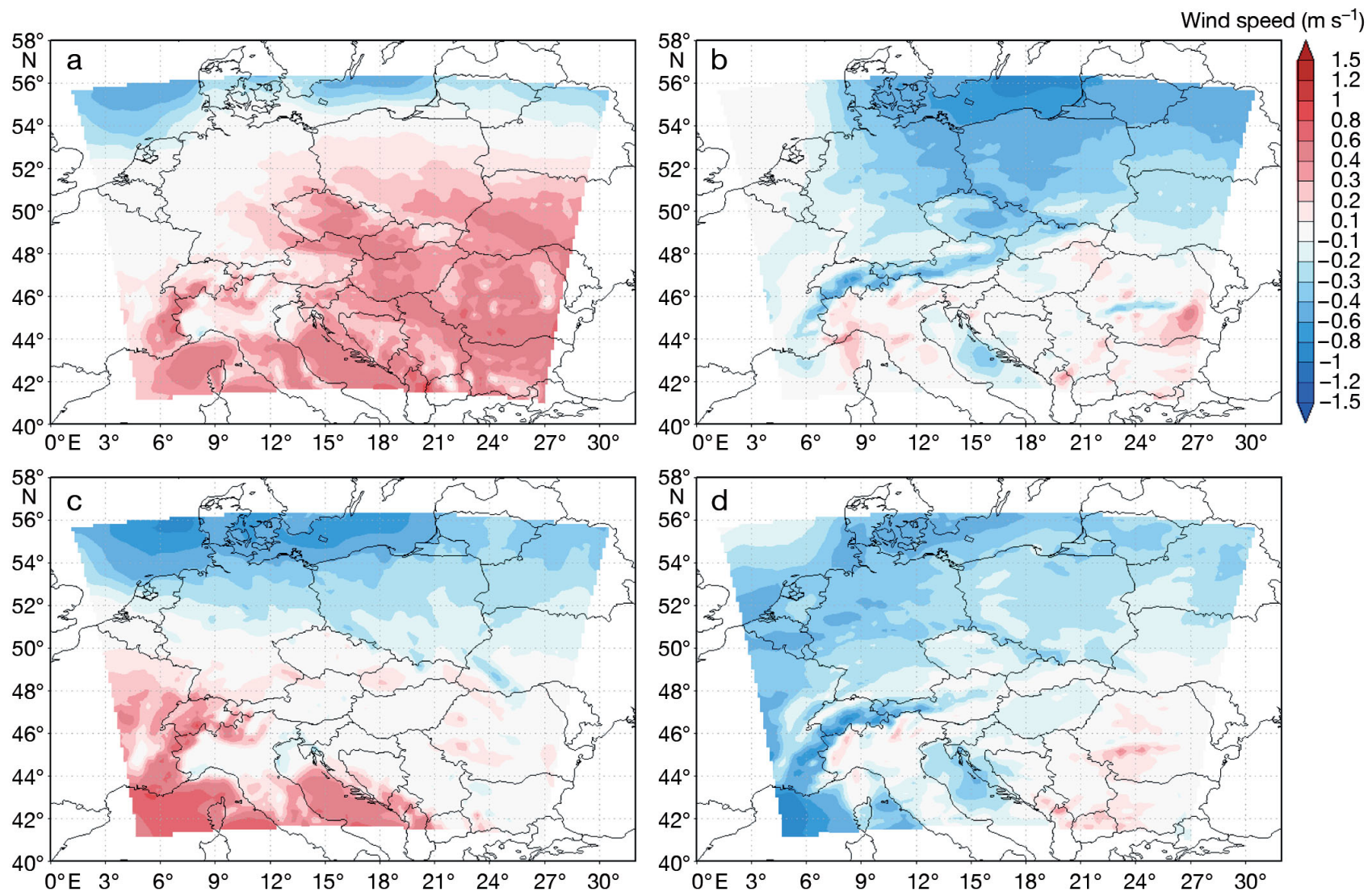

Fig. 9. Change in $(\mathrm{a}, \mathrm{c})$ zonal (west-east) and $(\mathrm{b}, \mathrm{d})$ meridional (south-north) surface wind between $(\mathrm{a}, \mathrm{b})$ 2041-2050 or $(\mathrm{c}, \mathrm{d})$ 2091-2100 and 1991-2000 as winter-autumn average (ECHAM runs)

wind changes significantly over the study regions, and only a slight decrease of the meridional wind component (up to $0.3 \mathrm{~m} \mathrm{~s}^{-1}$ ) occurs.

To also account for the possible changes in horizontal and vertical mixing that affect pollutant dispersion, we considered changes in the ventilation coefficient (VC), defined as the product of horizontal wind speed at the surface and the planetary boundary layer height (PBLH) according to Rao et al. (2003). In our simulations, the majority of the $\mathrm{SO}_{2}$ and $\mathrm{PM}_{10}$ exceedances occurred during winter and autumn, and the largest future changes occurred during these 2 seasons. Therefore, we evaluated the change in VC for these 2 seasons, as shown in Fig. 10. In the near 

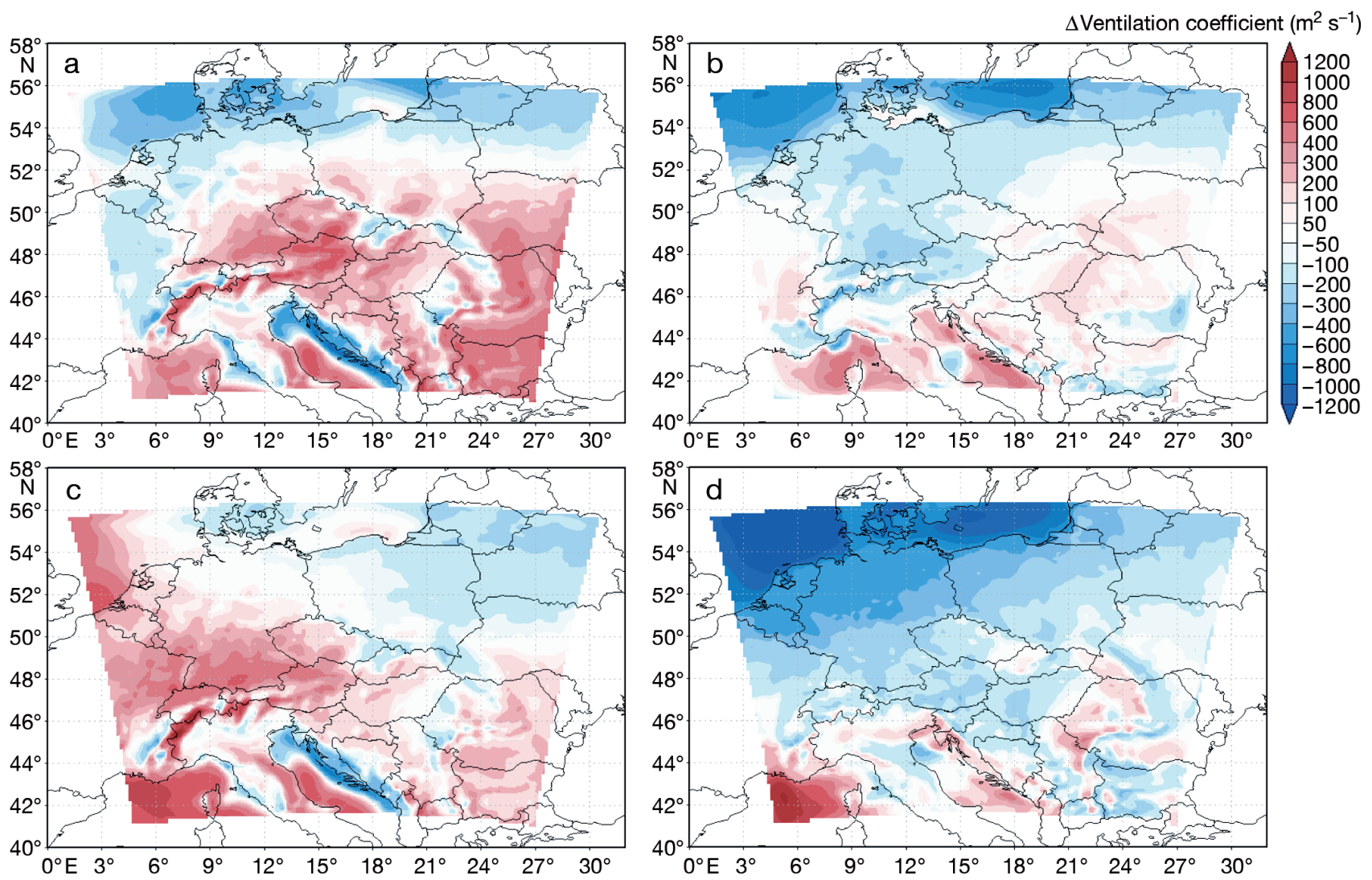

Fig. 10. Change in ventilation coefficient between (a,b) 2041-2050 or (c,d) 2091-2100 and 1991-2000 for (a,c) winter and (b,d) autumn (ECHAM runs)

future, VC increases in winter over the majority of the domain by up to $400 \mathrm{~m}^{2} \mathrm{~s}^{-1}$. In autumn, the change is not uniform, with a small increase in central Europe and areas of decrease over southeastern Europe. In the far future, the winter increase seen in the near future is suppressed and the autumn decrease intensifies, occurring over the majority of the domain (from 100 to $600 \mathrm{~m}^{2} \mathrm{~s}^{-1}$ ).

\subsection{Impact on ozone}

Climate change may affect agriculture and forestry through changes in AOT40. In our climate scenario, AOT40 will mostly decrease in the near future (Fig. 11). An increase occurs in AOT40 for crops in northern Italy and lowlands in Hungary and Serbia ranging from 200 to $1000 \mathrm{ppbv} \cdot \mathrm{h}$, which compared to the present-day absolute values in Fig. 2, represents a relative increase of 2 to $20 \%$.

A significant change in AOT40 due to climate change is modelled in the far future for the Czech domain plotted in Fig. 11. Large areas show an increase of AOT40 for crops, ranging from 100 to
$3000 \mathrm{ppbv} \cdot \mathrm{h}$, corresponding to a relative change of 5 to $30 \%$. The most affected areas are northern Italy, southern Germany and the Carpathian basin. A similarly large increase is modelled for forests, up to $4000 \mathrm{ppbv} \cdot \mathrm{h}$, representing a relative change up to $30 \%$.

An even higher increase of AOT40 for crops is calculated for the Hungarian domain. The average AOT40 for the control period and the change for the far future decade is plotted in Fig. 12. Comparing the present day and future values, a relative increase of 20 to $30 \%$ is modelled for large areas of the Czech and Slovak Republics, Hungary and Austria.

The number of days per year with $8 \mathrm{~h}$ ozone $>120 \mathrm{\mu g} \mathrm{m}^{-3}$ for the near future will increase by 1 to 2 $\mathrm{d}$ in central Europe and by up to $5 \mathrm{~d}$ in northern Italy (Fig. 13a). A much larger increase occurs in the far future decade (Fig. 13b). Again, northern Italy will suffer the most, being affected by an increase of 6 to $20 \mathrm{~d} \mathrm{yr}^{-1}$, but other influenced areas include southern Germany ( 4 to $6 \mathrm{~d} \mathrm{yr}^{-1}$ ) and the Czech Republic (2 to $4 \mathrm{~d} \mathrm{yr}^{-1}$ ). Compared to the absolute values in Fig. 3a, these changes are very large in a relative sense, often reaching $100 \%$. 

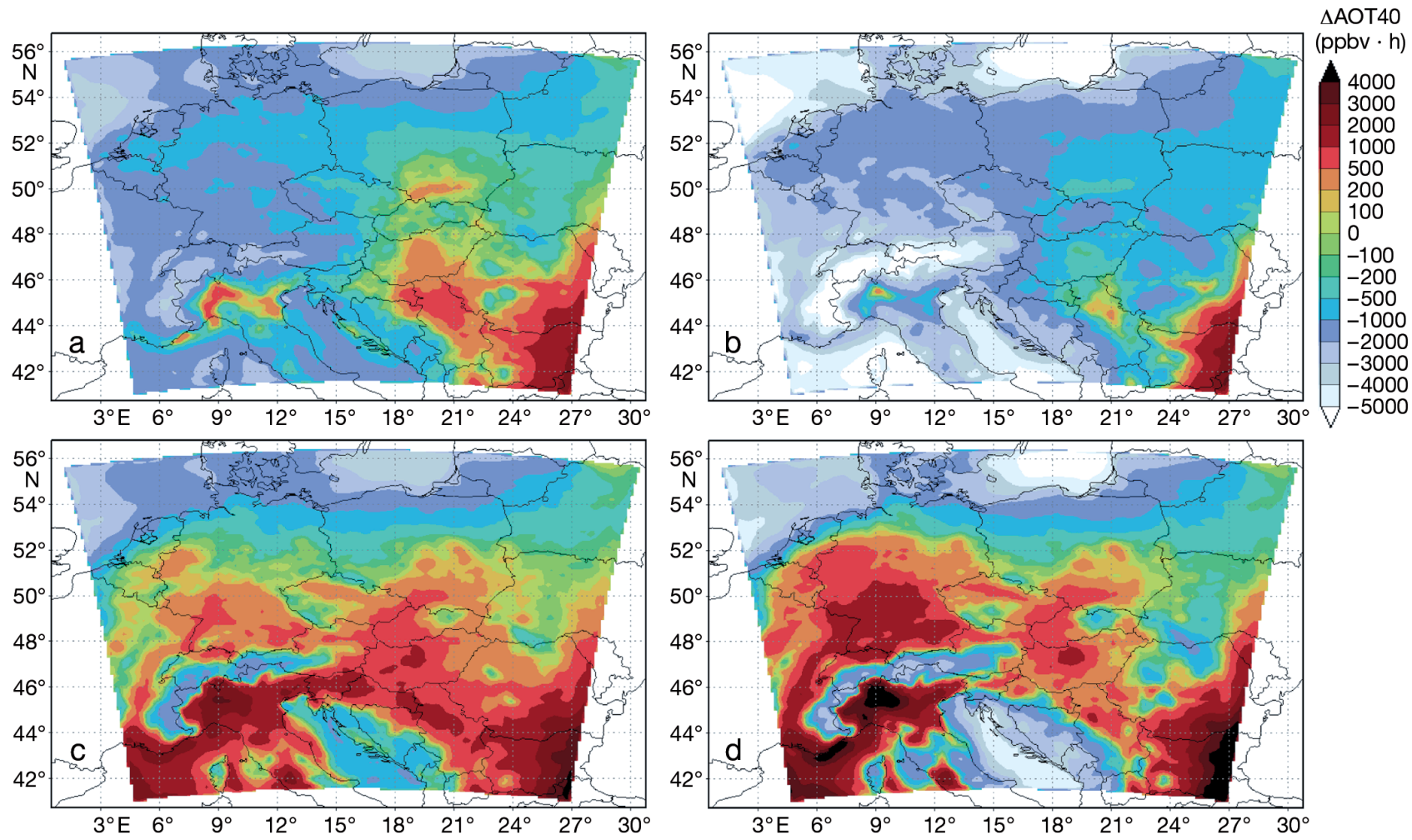

Fig. 11. Change in average AOT40 for $(a, c)$ crops and $(b, d)$ forests between $(a, b)$ 2041-2050 or (c,d) 2091-2100 and 1991-2000; all ECHAM runs with year 2000 emissions

The higher frequency of extreme temperature and heat waves in the future has the potential not only to change the number of exceedances, but also to push the ozone maximum towards higher values (Fig. 14). In the near future (Fig. 14a), this is not yet apparent. The average ozone annual maxima will be higher by up to 6 to 8 ppbv, usually by 0 to 3 ppbv in many regions of central and southeastern Europe. A much more intensive rise in ozone maxima due to climate change occurs in the far future (Fig. 14b). Over large areas, the increase will be as much as 4 ppbv, reaching 15 ppbv in northern Germany.

\subsection{Impact on sulphur dioxide}

Changes in the number of days when the surface $\mathrm{SO}_{2}$ concentration is higher than $125 \mathrm{\mu g} \mathrm{m}^{-3}$ (Fig. 15) appear mainly around the main $\mathrm{SO}_{2}$ emissions hotspots where the present values of the number of exceedances are also high, i.e. in southern Poland, northern Hungary and the Balkan countries. In the far future (Fig. 15b), the increase in the number of days with exceedances dominates (up to 5 to $6 \mathrm{~d} \mathrm{yr}^{-1}$ ), while in the near future (Fig. 15a), areas of decrease are also present, usually neighbouring areas of increase.
From Fig. 16, it is clear that the hourly EU threshold $\left(350 \mu \mathrm{g} \mathrm{m}^{-3}\right.$ ) will be exceeded more often in the future. This holds mainly for the region of southern Poland, with a change up to $+15 \mathrm{~h} \mathrm{yr}^{-1}$.

Fig. 17 plots areas of surface $\mathrm{SO}_{2}$ that exceed the annual $20 \mu \mathrm{g} \mathrm{m}^{-3}$ threshold for the control period (Fig. 17a) and for the far future decade (Fig. 17b) over the Bulgarian domain. Two regions of high annual $\mathrm{SO}_{2}$ appear around the thermal power plant (TPP) 'Mariza-Iztok' (a set of 3 coal-burning thermal power plants with a common name) and TPP 'Bobov dol'. There is no relevant change in the shape of these regions between the time slices, although in the far future a slight increase of the area is evident. The near future figure is not presented as it appears to be very similar to present-day conditions.

\subsection{Impact on particulate matter}

Future climate change also seems to alter surface $\mathrm{PM}_{10}$ concentrations despite no change in the emissions. According to Fig. 18, an increase by $1 \mathrm{~d} \mathrm{yr}^{-1}$ is modelled in the number of days when the $\mathrm{PM}_{10} \mathrm{EU}$ threshold of $50 \mathrm{\mu g} \mathrm{m}^{-3}$ is exceeded in many areas in both the near and far future. In the region of the 
AOT40 (ppbv $\cdot \mathrm{h})$

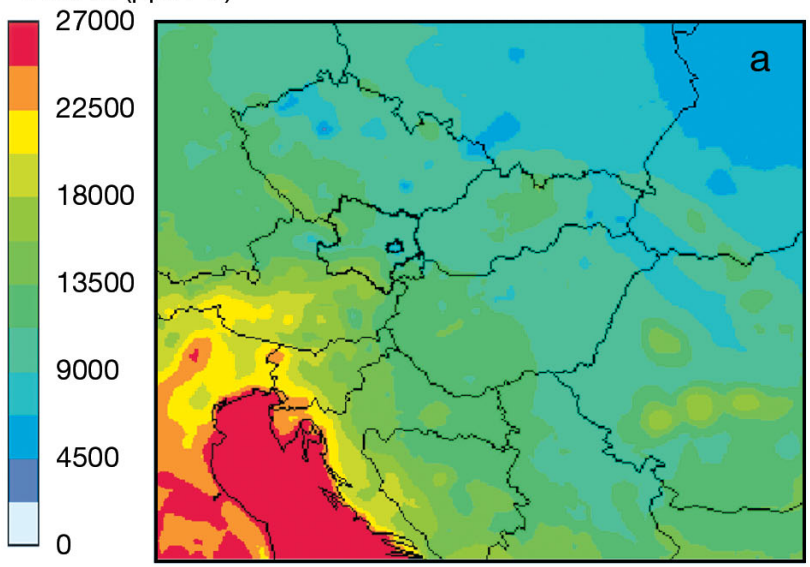

$\triangle \mathrm{AOT} 40(\mathrm{ppbv} \cdot \mathrm{h})$

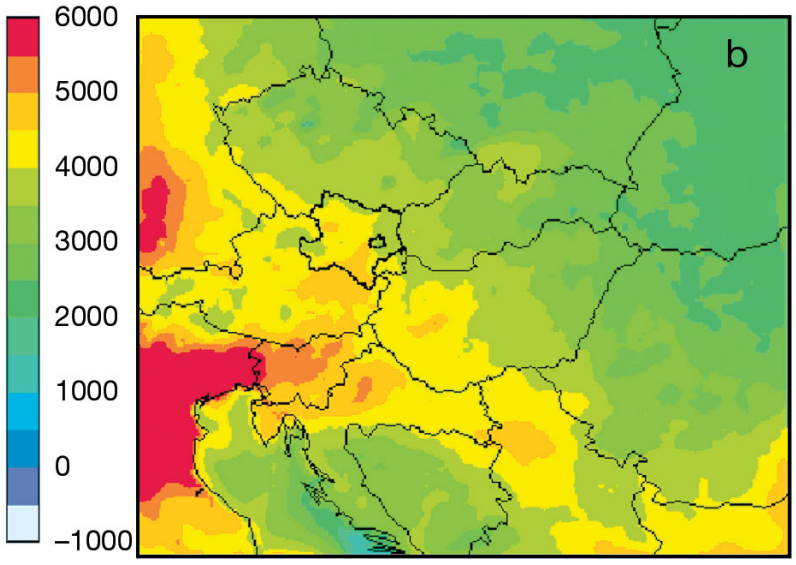

Fig. 12. AOT40 (May-July) for crops in the Hungarian domain (ECHAM runs); averaged over (a) 1991-2000 and (b) the change between 2091-2100 and 1991-2000 with year 2000 emissions. Borders within Austria indicate Lower Austria and the Vienna administrative region
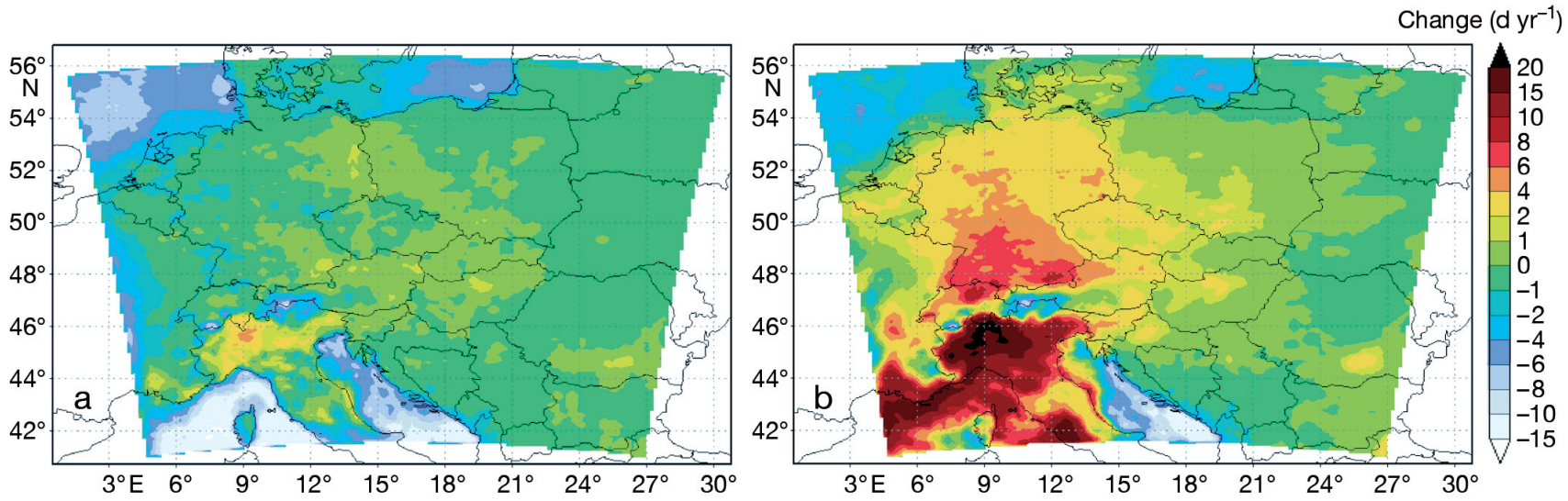

Fig. 13. Change in average number of days per year with maximum $8 \mathrm{~h}$ running ozone levels higher than $120 \mu \mathrm{g} \mathrm{m}{ }^{-3} \mathrm{between}$ (a) 2041-2050 or (b) 2091-2100 and 1991-2000 (ECHAM runs) with year 2000 emissions
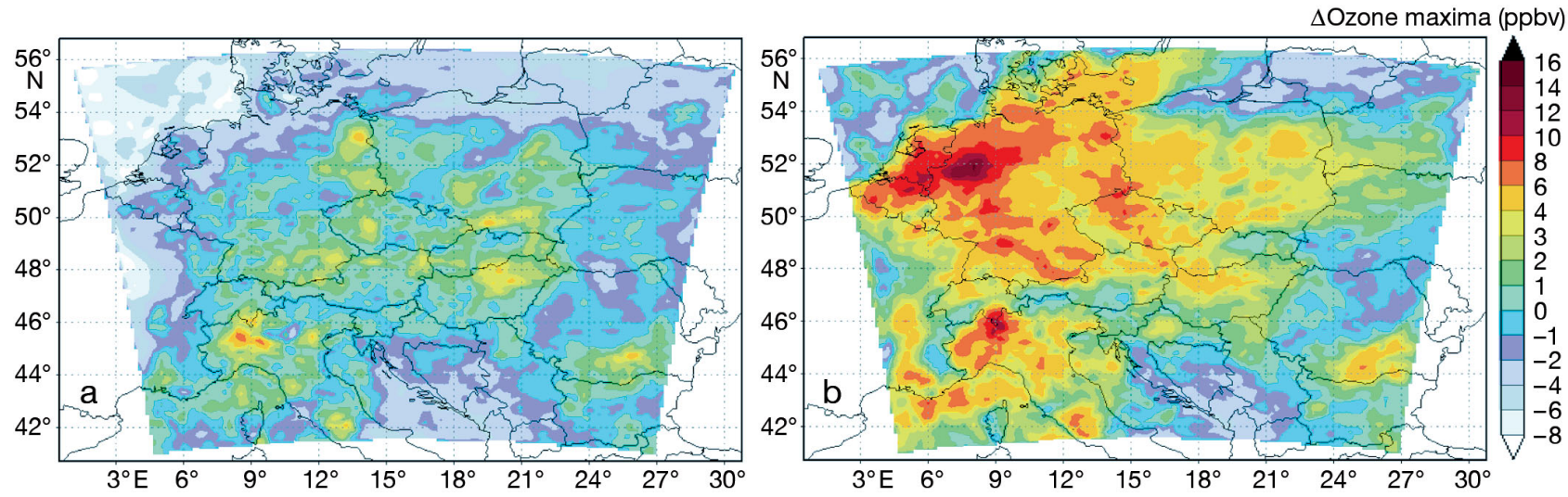

Fig. 14. Change in average annual ozone maxima between (a) 2041-2050 or (b) 2091-2100 and 1991-2000 (ECHAM runs) with year 2000 emissions 

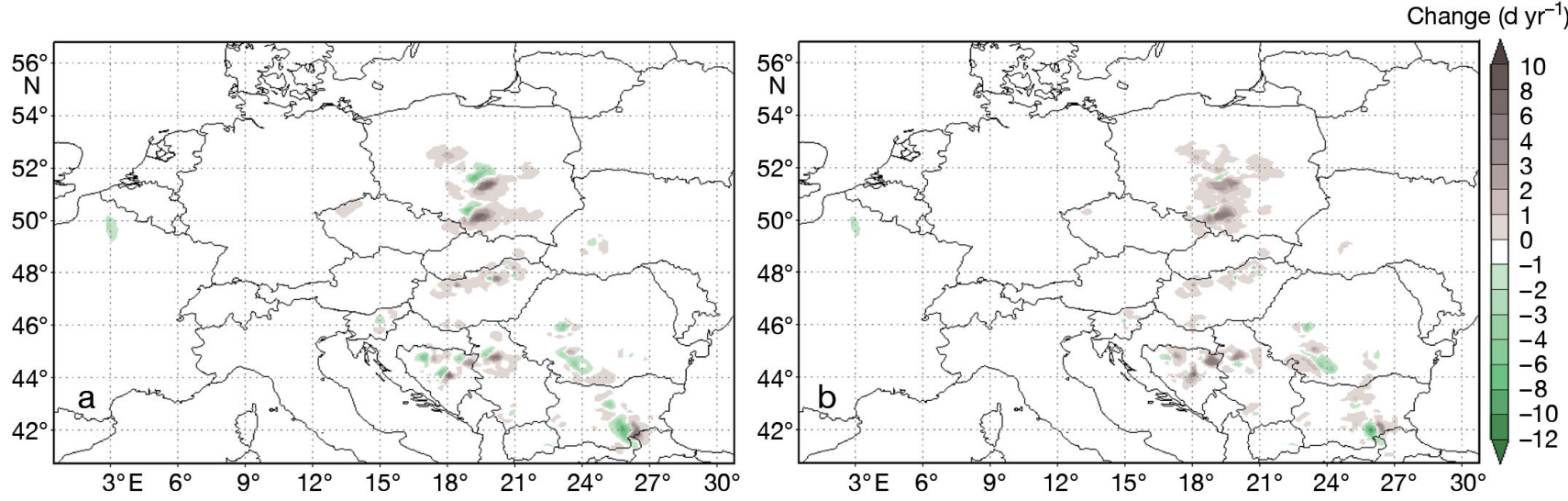

Fig. 15. Change in average number of days per year with daily $\mathrm{SO}_{2}$ level higher than $125 \mu \mathrm{g} \mathrm{m}^{-3}$ between (a) 2041-2050 or (b) 2091-2100 and 1991-2000 (ECHAM runs) with year 2000 emissions
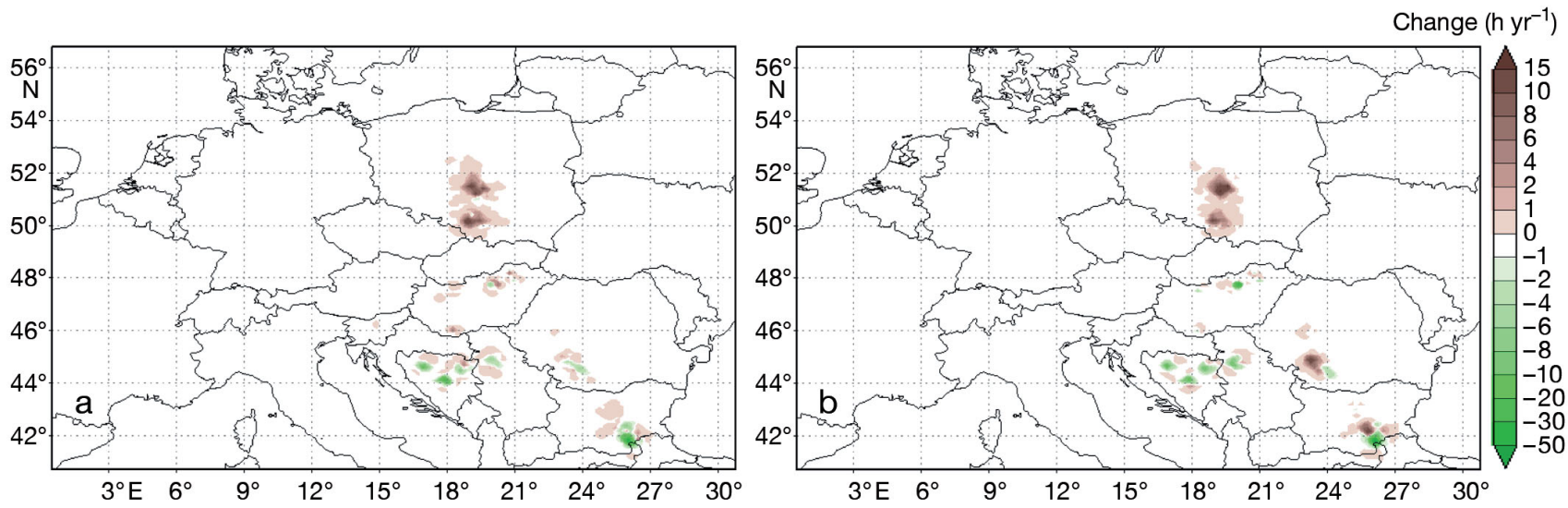

Fig. 16. Change in average number of hours per year with $\mathrm{SO}_{2}$ levels higher than $350 \mu \mathrm{g} \mathrm{m}^{-3}$ between (a) 2041-2050 or (b) 2091-2100 and 1991-2000 (ECHAM runs) with year 2000 emissions
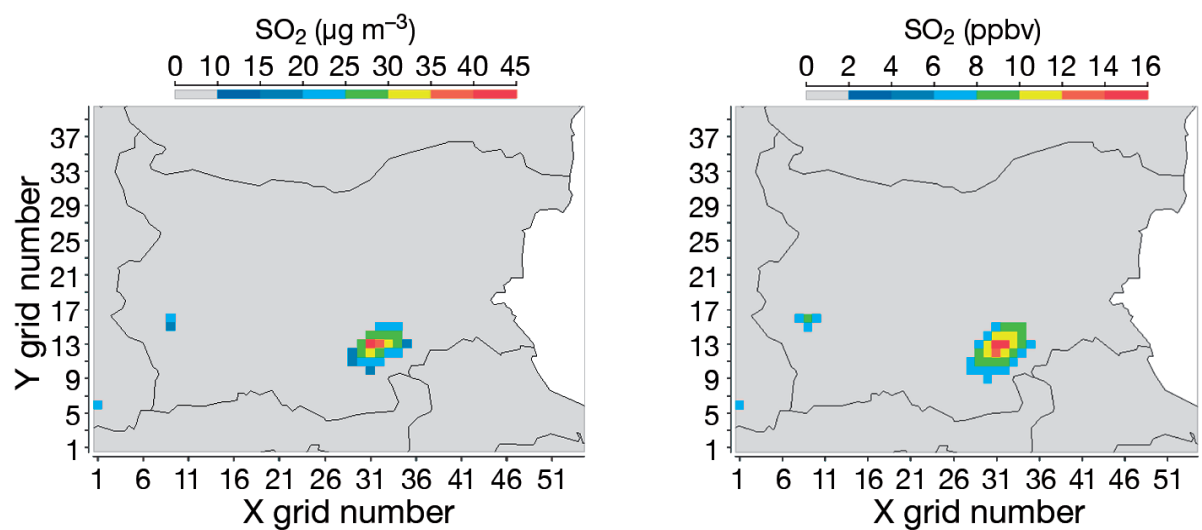

Fig. 17. Grid boxes with $\mathrm{SO}_{2}$ levels, showing exceedances of the $20 \mu \mathrm{g} \mathrm{m} \mathrm{m}^{-3}$ ( 7.6 ppbv) annual threshold in the Bulgarian domain (ECHAM runs); averaged over (a) 1991-2000 and (b) 2091-2100 with year 2000 emissions

Benelux countries, a decrease up to $3 \mathrm{~d} \mathrm{yr}^{-1}$ occurs in the far future. Particle matter concentrations in the Polish domain exhibit a different picture (Fig. 19). While in the outer part of the domain, no $\mathrm{PM}_{10}$ exceedance change is modelled, the central areas corresponding to Poland show decreased pollution in both the near and far future up to 10 to $15 \mathrm{~d} \mathrm{yr}^{-1}$. Only minor regions in the country's southern part show an increase by 1 to $5 \mathrm{~d} \mathrm{yr}^{-1}$, similar to results for the Czech domain.

\section{SUMMARY AND DISCUSSION}

The goal of this study was to investigate the effect of climate change on air pollution, assuming that anthropogenic emissions are kept at present-day levels. Selecting 1 present decade and 2 decades in the near and far future, we evaluated the changes in ozone, $\mathrm{SO}_{2}$ and particulate matter pollution. We focused on exceedances, exposure and maximum values rather than providing an assessment of average concentra- 

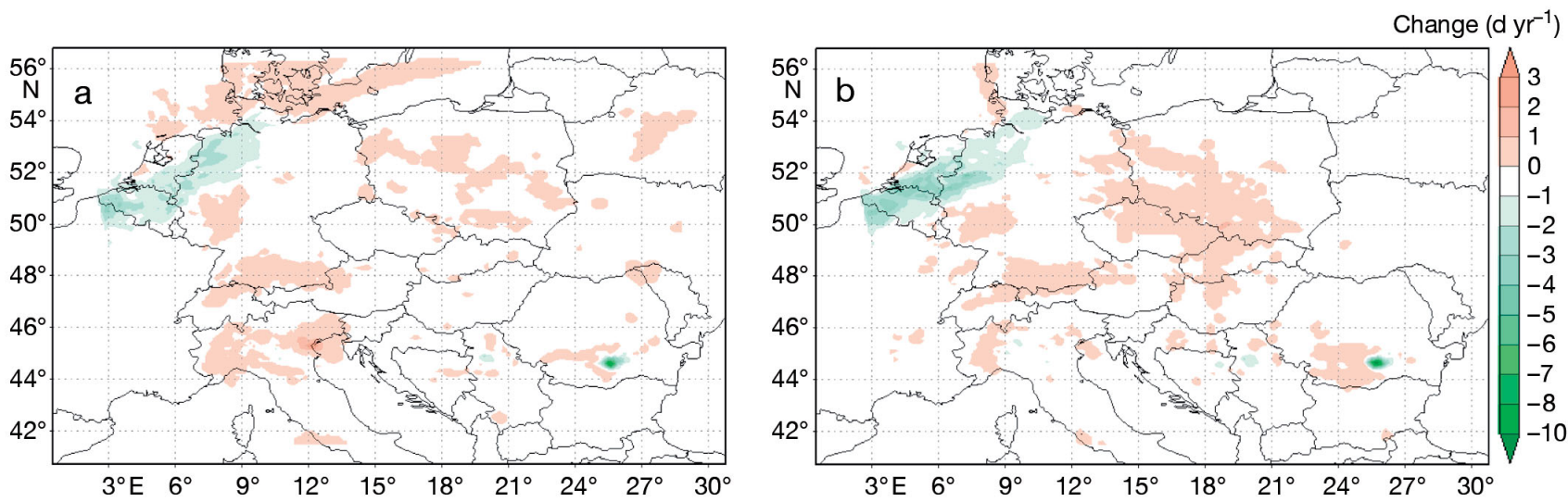

Fig. 18. Change in average number of days per year with $\mathrm{PM}_{10}$ levels $>50 \mu \mathrm{g} \mathrm{m}^{-3}$ between (a) 2041-2050 or (b) 2091-2100 and 1991-2000 (ECHAM runs) with year 2000 emissions
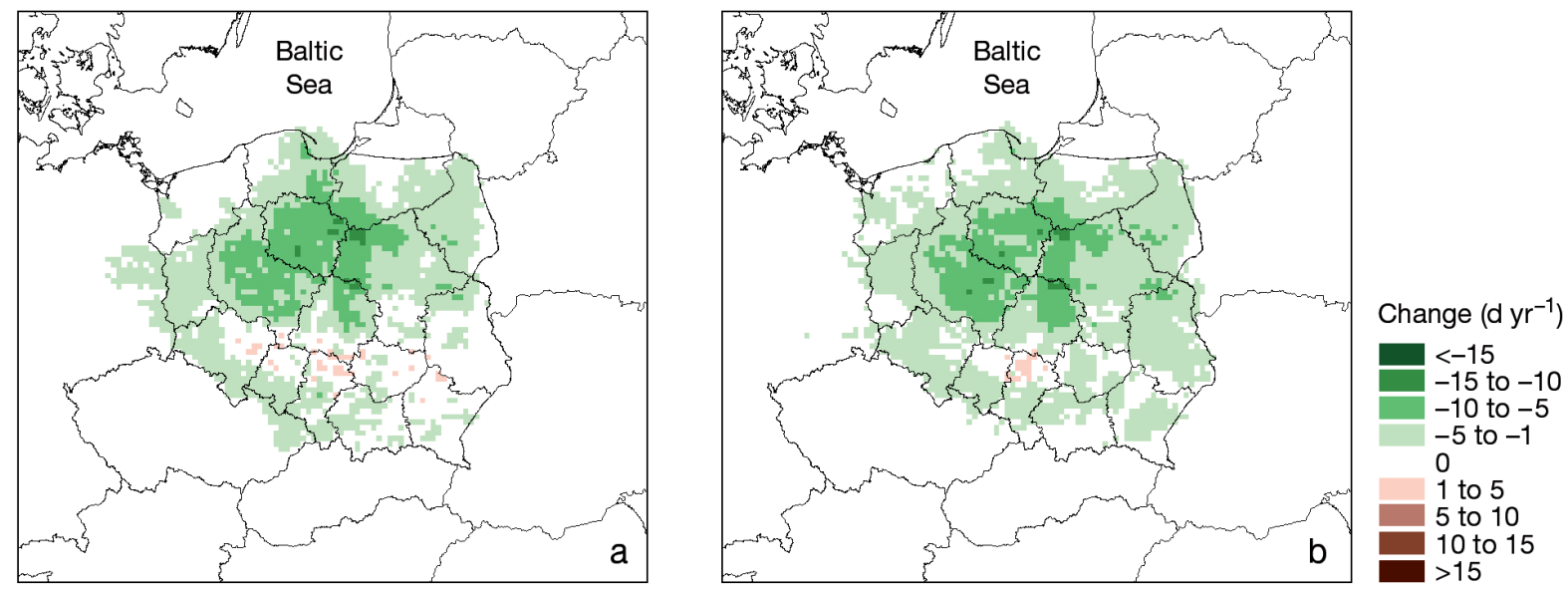

Fig. 19. Change in average number of days per year with $\mathrm{PM}_{10}$ levels $>50 \mu \mathrm{g} \mathrm{m}^{-3}$ between (a) 2041-2050 or (b) 2091-2100 and 1991-2000 for the Polish domain (ECHAM runs) with year 2000 emissions. Additional borders within Poland indicate the administrative regions (Voivodeships)

tion changes such as was carried out by Juda-Rezler et al. (in press). As highlighted by many previous studies, different meteorological conditions in the future climate can lead to modified pollutant levels. Indeed, we modelled changes in ozone, $\mathrm{SO}_{2}$ and $\mathrm{PM}_{10}$ surface patterns.

Due to elevated air temperatures seen in our simulations, AOT40s for crops and forests tend to increase, reaching changes up to 20 to $30 \%$ in many areas of central Europe by the end of the century. However, an increase in other parameters such as cloud optical depth can reduce ozone and counteract the temperature-induced changes as shown by Krüger et al. (2008). Indeed, in our simulations, AOT40s decrease in the near future, when the temperature increase is small and the solar incident radiation decreases.

An intense increase in the number of $8 \mathrm{~h}$ ozone threshold exceedances was also modelled. In some areas in the far future decade, this was up to 2 times the present-day value. Modelled ozone maxima are also higher in the future. The CAMx model simulated hourly ozone surface concentrations in the range of 0 to approximately $90 \mathrm{ppbv}$, and the modelled enhancement of ozone maxima is therefore significant in relative terms. Our results correspond to what e.g. Murazaki \& Hess (2006) found for future ozone affected by climate change. They showed for the USA that although average background ozone may decrease by only 0 to 2 ppbv in remote regions, significant increases in ozone exceedances are predicted, especially in the northeastern USA.

The modelled $\mathrm{SO}_{2}$ and $\mathrm{PM}_{10}$ changes can be partly attributed to different horizontal and vertical mixing, as was concluded earlier by Krüger et al. (2007) in the case of $\mathrm{PM}_{10}$. Daily exceedances of $\mathrm{SO}_{2}$ in the near future compared to the present decade show a shift of high pollution areas in a southern or southeastern 
direction. This indicates that a change in the average surface wind direction and speed has occurred. Indeed, as seen in the ventilation change pattern, for the near future it increases a little, and at the same time a larger increase in zonal (west-east direction) wind is predicted while the meridional wind decreases. In the far future, ventilation decreases in autumn over much of the domain except southern regions. This explains the more frequent violation of threshold values for both daily and hourly averages, especially over Poland. In summer, a decrease of VC can contribute to more frequent ozone exceedances. This occurred mainly in the far future decade, where $\mathrm{VC}$ in summer decreased by 200 to $400 \mathrm{~m}^{2} \mathrm{~s}^{-1}$ (corresponding to a 10 to $20 \%$ decrease) over many areas of Europe (data not shown).

In the spatial pattern of the climate changeinduced changes in surface $\mathrm{PM}_{10}$ exceedance, 3 regions can be distinguished, both for the near and far future. (1) A decrease occurs around the Benelux states and northwestern Germany (up to $3 \mathrm{~d} \mathrm{yr}^{-1}$ ). (2) Many parts of Europe encounter an insignificant

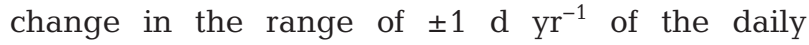
$\mathrm{PM}_{10}$ exceedance. (3) A significant local decrease in southern Romania can be clearly located. The latter can be explained by increasing ventilation in the region in the future causing $\mathrm{PM}_{10}$ to disperse more, eventually resulting in a slight increase in the number of exceedances around the area of decrease, probably related to local source effects. In the Benelux states, a large decrease was modelled for the average $\mathrm{PM}_{10}$, which can lead to suppressed potential for threshold violation.

A larger decrease (up to $15 \mathrm{~d} \mathrm{yr}^{-1}$ ) is calculated for both the near and far future over Poland in the Polish domain. This discrepancy can be explained by the different treatment of emissions in the Polish domain. LPSs (with a thermal input greater than $50 \mathrm{MW}_{\text {th }}$ ) were simulated separately in the CAMx model, while for the Czech domain all sources were simulated as area sources. This changed the distribution of maxima levels and simultaneously the number of exceedance-days in both simulations. It should be noted, however, that compared to the tolerated number of exceedances (35), discrepancies in the results are not significant.

We did not evaluate changes in wet deposition (removal by wet scavenging, i.e. uptake of gases and aerosols by cloud and rain droplets) in future decades; however, the modelled precipitation changes for the near future are very small, indicating that the simulated pollutant concentration changes are affected by changes in other meteorological parameters. In the far future, a decrease (increase) is predicted for summer (winter), in both cases representing a relative change up to $10 \%$. In summer this can contribute to suppressed wet deposition, resulting in more frequent ozone threshold violations and larger AOT values. Winter precipitation increases in line with the decrease patterns modelled for $\mathrm{PM}_{10}$ (over the Benelux region); however, the higher number of threshold exceedances for $\mathrm{SO}_{2}$ suggest that precipitation, and therefore wet deposition changes played a minor role.

The question arises as to how the simulated model deficiencies identified during the validation affect the simulated changes in selected air quality metrics due to climate change. In the case of ozone, it can be assumed that the underestimation of daily maximum values will persist in the future, significantly affecting the simulation of higher ozone episodes and AOTs. However, one can expect that the modelled changes expressed in a relative sense will eliminate this bias. In the case of $\mathrm{SO}_{2}$, our model overestimated winter values, while the future changes were attributed to modified horizontal and vertical mixing. Especially the decrease in the VC can have a larger impact when considering area emissions within the lowest model layer that caused this overestimation. $\mathrm{SO}_{2}$ emissions injected in higher model levels can be transported over larger distances, and the local decrease of ventilation will have a smaller effect. Indeed, over the Polish domain, no increases in $\mathrm{SO}_{2}$ exceedances in the far future were modelled. Finally, the changes in $\mathrm{PM}_{10}$ levels due to climate change were not attributed to changed formation rates of secondary aerosols, and are likely caused by changed wind and vertical mixing; therefore we can conclude that the simulated change would have been comparable (at least qualitatively) if the model had not underestimated certain types of aerosol. However, as already mentioned, one reason for the $\mathrm{PM}_{10}$ underestimation is the disregard of soil dust emissions; such emissions may undergo significant variation in the future due to climate change, thus changing the conclusions of this study (Tegen et al. 2004).

We again strongly emphasise that this study does not intend to make predictions for future air pollution, although it presents changes in policy-relevant metrics for the future. As seen within EMEP emissions or as presented by Riahi et al. (2007), future emissions will likely decrease. In the case of $\mathrm{NO}_{\mathrm{x}}$ and NMVOC emissions, it is difficult to judge how this will affect the final ozone concentration, as it is highly sensitive to the ratio of these emissions. For example, considering anthropogenic emissions and 
boundary condition modifications only, Szopa et al. (2006) predicted less extreme $\mathrm{O}_{3}$ episodes in the future, in contrast to our findings. They also present decreases in $\mathrm{SO}_{2}$ or carbonaceous aerosol emissions leading to decreases in heavy pollution events in the future, again in contrast to our results. Therefore, our results must be interpreted as one aspect of future air pollution variations. For example, decreases in $\mathrm{SO}_{2}$ emissions will result in lower concentrations and probably less exceedances; however, due to modified wind and vertical mixing, as seen in our study, this decrease will be suppressed. A similar conclusion can be made in the case of ozone. While future changes in precursor emissions follow the goal of reducing ozone, changed meteorological conditions due to climate change, as seen in our study, will favour more frequent ozone exceedances.

Consequently, when implementing policies to reduce pollutant levels, implications like those made in our study must be considered. Focusing only on emissions while neglecting the effect of climate change on air pollution may lead to inappropriate decisions in air quality management.

Acknowledgements. This study was supported under the framework of EC FP6 STREP CECILIA (GOCE 037005), as well as under a local grant from Programme Informacni spolecnost, no. 1ET400300414 and a Research Plan of MSMT under no. MSM 0021620860.

\section{LITERATURE CITED}

Andersson C, Engardt M (2010) European ozone in a future climate: importance of changes in dry deposition and isoprene emissions. J Geophys Res 115, D02303, doi: 10.1029/2008JD011690

Baker K, Timin B, Phillips S (2008) Operational evaluation and model response comparison of CAMx and CMAQ for ozone and PM2.5. 7th Annual CMAS Conference, Chapel Hill, NC, 6-8 October. Available at www.cmascenter.org/conference/2008/abstracts/baker_operational_ evaluation_cmas08.pdf

- Bell ML, Goldberg R, Hogrefe C, Kinney PL, Knowlton K, Lynn B (2007) Climate change, ambient ozone, and health in 50 US cities. Clim Change 82:61-76

Byun DW, Kim ST, Kim SB (2007) Evaluation of air quality models for the simulation of a high ozone episode in the Houston metropolitan area. Atmos Environ 41:837-853

Carter WPL (1996) Condensed atmospheric photooxidation mechanisms for isoprene. Atmos Environ 30:4275-4290

Collins WJ, Derwent RG, Garnier B, Johnson CE, Sanderson MG, Stevenson DS (2003) Effect of stratosphere-troposphere exchange on the future tropospheric ozone trend. J Geophys Res 108, 8528, doi:10.1029/2002JD002617

> Dawson JP, Adams PJ, Pandis SN (2007) Sensitivity of ozone to summertime climate in the eastern USA: a modeling case study. Atmos Environ 41:1494-1511
Denby B, Schaap M, Segers A, Builtjes P, Horálek J (2008) Comparison of two data assimilation methods for assessing PM10 exceedances on the European scale. Atmos Environ 42:7122-7134

EMEP (European Monitoring and Evaluation Programme) (2010) EMEP/CCC Reports 1975-2010. Available at www.nilu.no/projects/ccc/reports.html

Fiore AM, Horowitz LW, Purves DW, Levy H and others (2005) Evaluating the contribution of changes in isoprene emissions to surface ozone trends over the eastern United States. J Geophys Res 110, D12303, doi:10.1029/ 2004JD005485

Flemming J, Stern R (2007) Testing model accuracy measures according to the EU directives: examples using the chemical transport model REM-CALGRID. Atmos Environ 41:9206-9216

Fuhrer J, Skärby L, Ashmore MR (1997) Critical levels for ozone effects on vegetation in Europe. Environ Pollut 97:91-106

Grell G (1993) Prognostic evaluation of assumptions used by cumulus parameterizations. Mon Weather Rev 121: 764-787

> Guenther AB, Zimmermann PC, Harley R, Monson RK, Fall R (1993) Isoprene and monoterpene emission rate variability: model evaluations and sensitivity analyses. J Geophys Res 98:12609-12617

Hauglustaine DA, Lathiere J, Szopa S, Folberth GA (2005) Future tropospheric ozone simulated with a climatechemistry biosphere model. Geophys Res Lett 32, L24807, doi:10.1029/2005GL024031

Hedegaard GB, Brandt J, Christensen JH, Frohn LM, Geels C, Hansen KM, Stendel M (2008) Impacts of climate change on air pollution levels in the Northern Hemisphere with special focus on Europe and the Arctic. Atmos Chem Phys 8:3337-3367

> Hunova I, Livorova H, Ostatnicka J (2003) Potential ambient ozone impact on ecosystems in the Czech Republic as indicated by exposure index AOT40. Ecol Indic 3:35-47

IPCC (2007) Climate change 2007: the physical science basis. Contribution of Working Group I to the Fourth Assessment Report of the Intergovernmental Panel on Climate Change. Cambridge University Press, Cambridge

Juda-Rezler K, Trapp W, Reizer M (2010) Modelling the impact of climate changes on PM levels in Poland. In: Steyn DG, Rao ST (eds) Air pollution modeling and its application XX. Springer, San Francisco, CA, p 509-514

Juda-Rezler K, Reizer M, Huszar P, Krüger BC and others (2012) On the effect of climate change on regional air quality over central-eastern Europe: concept, evaluation and future projections. Clim Res (in press)

Katragkou E, Zanis P, Tegoulias I, Melas D and others (2010) Decadal regional air quality simulations over Europe in present climate: near surface ozone sensitivity to external meteorological forcing. Atmos Chem Phys 10: 11805-11821

Krüger BC, Irene S, Formayer H, Moshammer H (2007) Feinstaub und Klimawandel: Gibt es Zusammenhänge in Nordost Österreich? StartClim2006-A Project Report. Universität für Bodenkultur, Department für Wasser Atmosphäre - Umwelt, Institut für Meteorologie, Wien

Krüger BC, Katragkou E, Tegoulias I, Zanis P and others (2008) Regional photochemical model calculations for Europe concerning ozone levels in a changing climate. Q J Hung Meteorol Serv 112:285-300

Mahmud A, Tyree M, Cayan D, Motallebi N, Kleeman MJ 
(2008) Statistical downscaling of climate change impacts on ozone concentrations in California. J Geophys Res 113:D21103. doi:10.1029/2007JD009534

Meleux F, Solmon F, Giorgi F (2007) Increase in summer European ozone amounts due to climate change. Atmos Environ 41:7577-7587

Murazaki K, Hess P (2006) How does climate change contribute to surface ozone change over the United States? J Geophys Res 111:D05301. doi:10.1029/2005JD005873

$>$ Nenes A, Pandis SN, Pilinis C (1998) ISORROPIA: a new thermodynamic equilibrium model for multiphase multicomponent inorganic aerosols. Aquat Geochem 4:123-152

Nolte CG, Gilliland AB, Hogrefe C, Mickley LJ (2008) Linking global to regional models to assess future climate impacts on surface ozone levels in the United States. J Geophys Res 113:D14307. doi:10.1029/2007JD008497

O'Brien JJ (1970) A note on the vertical structure of the eddy exchange coefficient in the planetary boundary layer. J Atmos Sci 27:1213-1215

Pal JS, Giorgi F, Bi X, Elguindi N and others (2007) Regional climate modeling for the developing world: the ICTP RegCM3 and RegCNET. Bull Am Meteorol Soc 88: 1395-1409

Querol X, Alastuey A, Ruiz CR, Artinano B and others (2004) Speciation and origin of PM10 and PM2.5 in selected European cities. Atmos Environ 38:6547-6555

Racherla PN, Adams PJ (2006) Sensitivity of global tropospheric ozone and fine particulate matter concentrations to climate change. J Geophys Res 111:D24103. doi: 10.1029/2005JD006939

Racherla PN, Adams PJ (2008) The response of surface ozone to climate change over the Eastern United States. Atmos Chem Phys 8:871-885

Rao ST, Ku JY, Berman S, Zhang K, Huiting M (2003) Summertime characteristics of the atmospheric boundary layer and relationships to ozone levels over the eastern United States. Pure Appl Geophys 160:21-55

Riahi K, Gruebler A, Nakicenovic N (2007) Scenarios of long-term socio-economic and environmental development under climate stabilization. Technol Forecast Soc Change 74:887-935

Editorial responsibility: Filippo Giorgi,

Trieste, Italy
Simpson D, Yttri KE, Klimont Z, Kupiainen K and others (2007) Modeling carbonaceous aerosol over Europe: analysis of the CARBOSOL and EMEP EC/OC campaigns. J Geophys Res 112:D23S14. doi:10.1029/2006JD 008158

Stevenson DS, Dentener FJ, Schultz MG, Ellingsen K and others (2006) Multimodel ensemble simulations of present-day and near-future tropospheric ozone. J Geophys Res 111:D08301. doi:10.1029/2005JD006338

Syrakov D, Prodanova M, Miloshev N, Ganev K and others (2010) Climate change impact assessment of air pollution levels in Bulgaria. Lect Notes Comp Sci 5910:538-545

- Szopa S, Hauglustaine DA, Vautard R, Menut L (2006) Future global tropospheric ozone changes and impact on European air quality. Geophys Res Lett 33, L18805, doi: 10.1029/2006GL025860

Tegen I, Werner M, Harrison SP, Kohfeld KE (2004) Relative importance of climate and land use in determining present and future global soil dust emission. Geophys Res Lett 31, L05105, doi:10.1029/2003GL019216

Uppala SM, Kållberg PW, Simmons AJ, Andrae U and others (2005) The ERA-40 re-analysis. Q J R Meteorol Soc 131: 2961-3012

USEPA (US Environmental Protection Agency) (2009) Assessment of the impacts of global change on regional US air quality: a synthesis of climate change impacts on ground-level ozone (an interim report of the US EPA Global Change Research Program). EPA/600/R-07/094F. US Environmental Protection Agency, Washington, DC

Vestreng V, Breivik K, Adams M, Wagener A, Goodwin J, Rozovskaya O, Pacyna JM (2005) Inventory review 2005: emission data reported to LRTAP Convention and NEC Directive, Initial review of HMs and POPs. Tech Rep EMEP MSC-W 1/2005. Available at www.emep.int/publ/ reports/2005/emep_technical_1_2005.pdf

Winiwarter W, Zueger J (1996) Pannonisches Ozonprojekt, Teilprojekt Emissionen, Endbericht, Report OEFZS-A3817. Austrian Research Center, Seibersdorf

Zlatev Z (2009) Impact of future climatic changes on high ozone levels in European suburban areas. Clim Change 101:447-483

Submitted: November 24, 2010; Accepted: July 26, 2011

Proofs received from author(s): November 17, 2011 